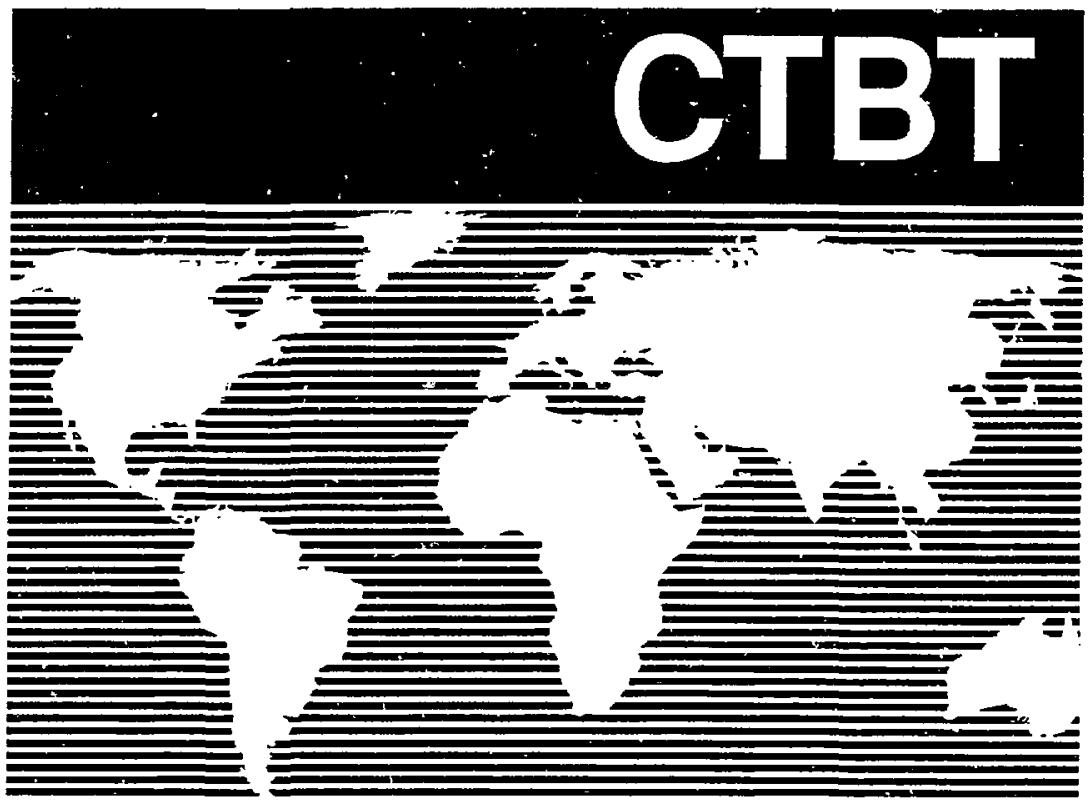

\title{
TECHNICAL ISSUES HANDBOOK
}

Department of Energy

Office of Intelligence

and National Security

UCRL-ID-117293 


\section{Acknowledgments}

We would like to thank Dorothy Donnelly of the Department of Energy's Office of Nonproliferation and National Security for encouraging us in this project.

The following people formed the publication staff for the CIBT Techrical Issues Handbook.

Scientific Editor

John ]. Zucea

Contributors

Charles R. Carrigan

Philip E Harben

David B. Harris

Jarnes F. Morgan

Albert T. Smith

Padmini Sokkappa

John ]. Zucca

Publication Editor

Susan P. Stull

Art/Design

Frank Uhlig

Irene J. Chan

Composition

Marion Capobianco

Publication

Lawrence Livermore

National Laboratory 


\section{Contents}

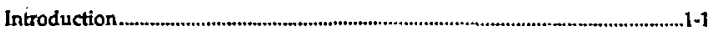

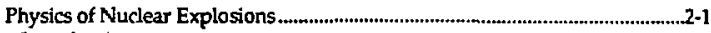

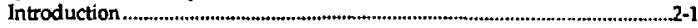

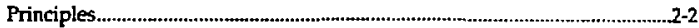

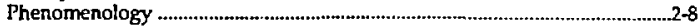

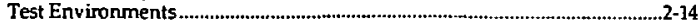

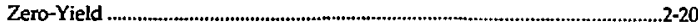

Other Nuclear Experiments...........................................................................3-1

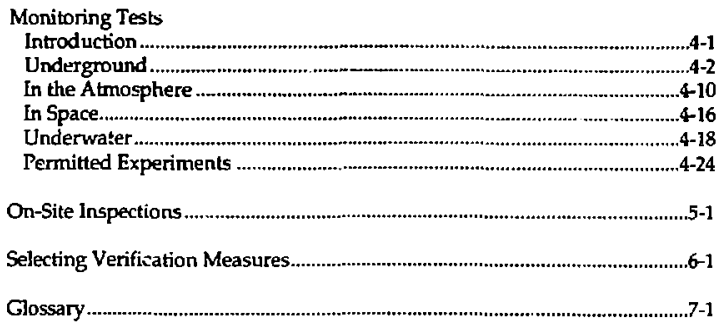


$\mathrm{T}$ The purpose of this handbrok is to give the nonspecialist in nuclear explosion physics and nuclear test monitoring an introduction to the topic as it pertains to a Comprehersive Test Ban Treaty (CTBT).

We have tried to make the handbook vistially oriented, with figures paired to short discussions. As such, the handbook may be read straight through or in sections Essentially, each figure with associated text stands alone.

The handbook covers four nuitin areas and ends with a glossary, which includes both scientific terms and acronyms likely to be encountered during CTBT negotiations. The rollowing topics are covered:

- Physics of nuclear explosion experiments. This is a description of basic nuclear physics and elementary nuclear weapon design. Also discussed are testing practices.

- Other nuclear experiments. This section discusses experiments that produce small amounts of nuclear energy but differ from explosion experiments discussed in the first chapter. This includes the type of activities, such as laser fusion, that would continue after a CTBT is in force.

- Monitoring tests in various environments. This section describes the different physical environments in which a test could be conducted (underground, in the atmosphere, in spacs, underwater, and in the laboratory); the sources of non-nuclear events (such as earthquakes and mining operations); and the opportunities for evasion. - On-site inspections. A CTBT is likely to include these inspections as an element of the verification provisions, in order to resolve the nature of ambiguous events. This chapter describes some technical considerations and technologies that are likely to be useful.

- Selecting verification measures. This chapter discusses the uncertain nature of the evidence from monitoring sys terrs and how compliance judgments could be made, taking the uncertainties into account. It alse discusses how to allocate monitoring resources, given the likelihood of testing by various countries in various environments.
A brief history of CTB negotiations

The current talks sponsored by the Conference on Disarmament are the world's third attempt at a complete ban cn nuclear testing. The first attempt was in the late 1950 s and early 1960 s. During this attempt both the U.S. and the Soviet Union entered into a testing nuratorium, which ended when the French began testing in North Africa. Although a CTB was not concluded, the Limited Test Ban Treaty between the U.S. and Soviet Union was completed in 1963.

The second attempt at a CTB was during the late 1970s under the Carter administration. These trilateral talks among the U.S., the Soviet Union, and the United Kingdom were broken off shortly after the Soviets invaded Afgharistan.

The current multilateral talks are being carried out during a nuclear testing moratorium observed by the U.S., Russia, Frarice, and the U.K.

For a more complete discussion of events relevant to the history of CTB negotiations, see A Chronology of Comprefiensive Test Ban Proposals, Negotiations, and Debates: 1945-199.3, Timothy J. Pounds, Science Applications International Corporation, McLean Virginia, January 1994.

\section{A note about this document}

The Handbcok is subject to revision as circumstances dictate. Please direct comments to either the scientific or publication editor at (510) 422-4895 and (510) 422-6583, respectively. 


\section{Introduction}

Nuclear energy is produced by either splitting (fissioning) the atomic nuclei of certain heavy elements or fusing the nuclei of light elements. The latter mode of energy production is responsible for the continuing output of energy in its various forms from the stars. Nuclear fission reactors are currently a source of commercial electricity in many countries of the world. The fusion process is recognized by a number of countries as a potential source for meeting both civilian energy requirements and those associated with defense and other military purposes.

This chapter acquaints the reader with aspects of the physics, engineering and phenomenology of nuclear explosions as well as some of the motivations for testing.

We begin the chapter by considering some of the physical principles of nuclear devices. Next, the phenomenology of the older, uncontained weapons experiments is summarized to complement the verification-related presentations on the phenomenology of contained underground tests in later chapters. Ocean, atmospheric, and space tests were carried out by the U.S. until the early 1960s, and their phenomenology requires monitoring procedures that vary from those developed for contained underground nuclear tests. The third section treats the environments of contained tests and their associated surface-structure facilities. Finally, we describe a category of weapons-related experiments characterized by an almost negligible (e.g., hundredths of a pound or even vanishing) nuclear yield. In the past, this category has been important for the U.S. nuclear program, and, in the context of a comprehensive test ban, it could assume new prominence. 


\section{Physics of Nuclear Explosions: Principles}

\section{Fission: concept of neutron loss reduction and critical mass for detonating nuclear weapons}

The nuclei of certain heavy isotopes, such as uranium- 235 and plutonium-239, are subject to neutron-induced fissioning. Capture of a neutron can cause breaking apart of the atomic nucleus to produce fragmentation products including an additional two or three neutrons pius excess en!rgy. The energetic neutrons from one fission may then be available for c:pture by other heavy nuclei to induce further fissioning. This in tum increases the population of free neutrons available for a chain reaction and results in an even higher rate of fissioning and free neutron production. If this process "runs away" ( a positive feedback state between neutroninduced fissioning and free neutron production rate), temendous amounts of nuclear energy can be liberated over an exceedingly short period of time. In fact, the detonation of a nuclear weapun requires that the fissioning process achieve a runaway state. This process contrasts with a nuclear reactor that produces a more or less constant output of energy as a result of a controlled rate of fissioning,

If neutrons are lost from a fissioning mass as fast as they are produced, multiplication of the free neutron population leading to runaway will not occur. For any given mass of fissionable material, neutrone will be lost through the surface of the mass to the outside. If the rate of loss is suddenly reduced relative to the rate of free neutron production, so that the rate of fissioning achieves a runaway state, a supercritical mass has been achieved. Adding to an amount of fissioning material is just one way to produce a critical mass (see figure). Reducing the surface area through which neutrons are lost is yet another way to achieve a critical mass. Both stockpiled and test devices employ one of the two approaches to achicve a runaway state leading to a nuclear detonation.

\section{Adding mass to produce supercriticality: the gun assembly approach}

The older and less efficient means of achieving a supercritical mass involves propelling one subcritical mass into another subcritical mass. The ratio of the area to the volume for the final mass is decreased relative to the ratio characterizing the masses separately. 


\section{Physics of Nuclear Explosions: Principles}
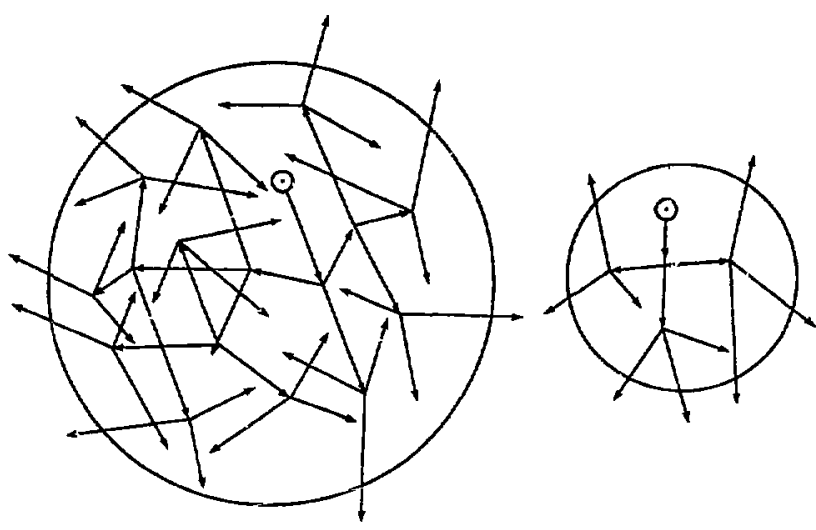

Increasing the mass of fissionable materiai increases the ratio of free neutrons available tor chain reactions to treo neutrons lost through the sur-

face. (From

S. Glasstone and P. J. Dolan, The Effects of Nuclear Weapons, U.S. Depts. of Doiense and Energy, U.S. GPO,1977.)

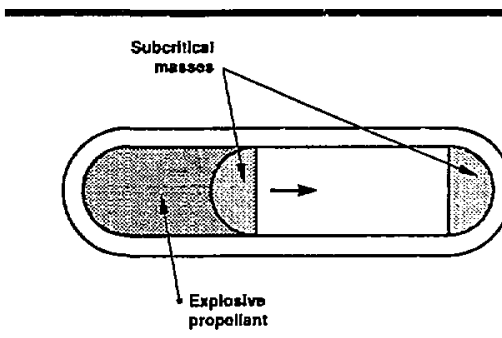

[Belore [ring]
Supercrtiteal

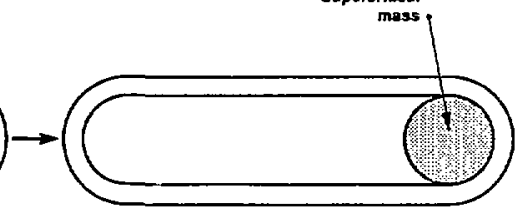
Then explodes

The gun ass6, nbly design for achieving a supercitical mass brings two subcritical fissioning components together via a projectile and target arrangement. (From Glassione and Dolan) 


\section{Physics of Nuclear Expiosions: Principles}

\section{Surface-area reduction to produce supercriticality: the implosion approach}

A more typical design for a nuclear weapon involves the implosion of a suberitical fissioning mass, sometimes called the pit, to produce a runaway, supercritical mass. Implosion of the pit is accomplished by detonating a shaped, high-explosive charge that surrounds the pit (see figure). Early weapons that depended on this approach to achieve a supercritical mass tended to be quite large physically (approximately $10,000 \mathrm{lb}$ ) to achieve yields in the 10-kiloton ( $k t)$ range.

\section{Fusion: another source of nuclear energy}

In the fission process, a heavy nucleus splits to release energy. In the case of fusion, a light nucleus combines with another light nucleus for a net release of energy. An atom of deuterium (hydrogen with an extra neutron) and an atom of tritium (hydrogen with two extra neutrons) can fuse under conditions of very high temperature and pressure to produce a helium nucleus (alpha particle), a neutron, and energy (17.6 MeV). An MeV is a unit of energy equal to $1.6 \times 10^{-13}$ joules. 


\section{Physics of Nuclear Explosions: Principles}

(a)

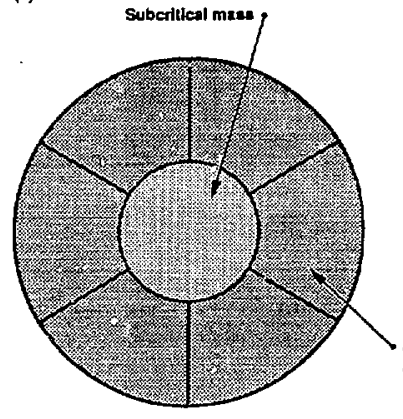

Betore fiting (b)

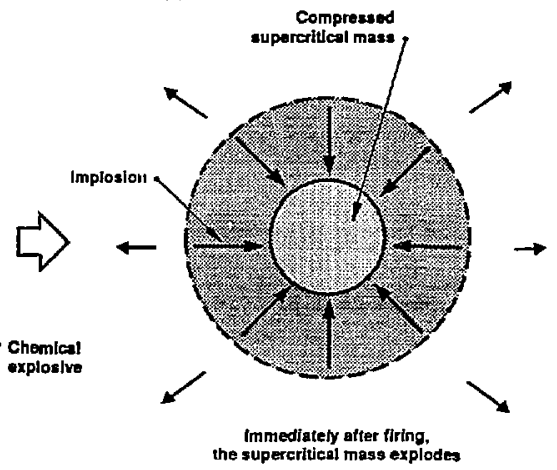

The implosion device design depends on reducing surface area by increasing density to achieve a supercritical mass. (From Glasstone and Dolan)

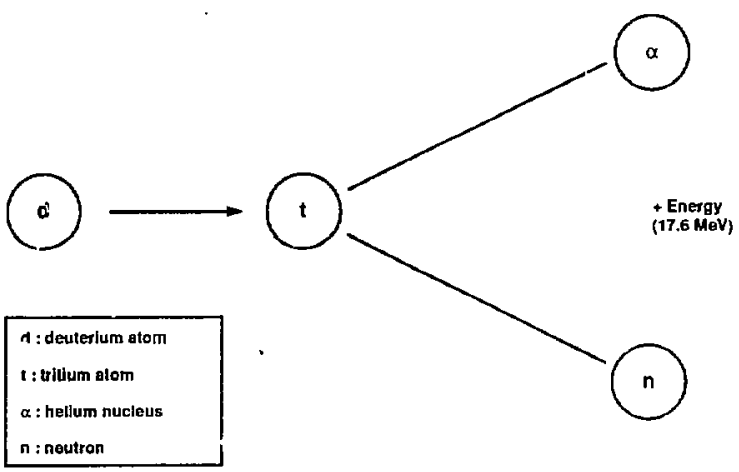

Schematic of a fusion reaction involving atoms of deuterium and tritium. Ulider the conditions of temperature and pressure produced by a fissioning device. fusion reactions can occur that produce producis of higher atomic mass (helium nuclei) and energetic neutrons. 


\section{Boosting: using fusion to enhance the rate of fissioning}

In the eaily 1950s, boosted fission weapons were deployed that had the advantage of being both smaller and lighter, for a given yield, than the early fission weapons. Enhanced yield was achieved with a smaller pit by enhancing fission rates in the imploding mass. This enhancement was produced by bombardment with 14.1-MeV neutrons prociuced by the initiation of a fusion reaction between deuterium and tritium gas located in the hollow center of the pit. The actual energy gained from the fusion component of a boosted fis sion weapon is small, but the enhancement of the fission component is large. 


\section{Physics of Nuclear Explosions: Principles}

\section{The thermonuclear device}

A thermonuclear device, often refersed to as a hydrcgen bornb, incorporates both the fission and fusion processes in primary and secondary stagrs. The development of a thermonuclear weapon was a strategically significant accomplishment. Compared to early atomic weapons, an extremely cơmpact, high-yield package could be produced. For example, yield of the earli. est pure fission devices was in the 10-20 kiloton range. Later transportab'c thermonuclear devices increased yield into the 100-kiloton to megato: range. At the same time, the weapon had to beconie smaller to be accommodated in ICBM designs. 


\section{Physics of́ Nuclear Explosions: Phenomenology}

\section{Atmospheric tests: early-stage detonation phenomena}

The first nuciear device was detonated on a tower in Alamogordo, New Mexico, in 1945. Most other subsequent tests carrieco out by the U.S. and the USS.R were above turface until the early 1960 s.

During the first fraction of a second following detonation, a fiteball is produced by the interaction of the atmosphere and the initial $x$-ray emission from the bomb. The heated ait reemits the thermal energy in the visial and infrared spectra. The light history from the fireball is a characteristic of atmospheric tests that distinguishes tinem from other high-energ. events such as chemical explosions and lightning bolts.

\section{Atmospheric tests: the double-flash phenomenon}

Amplifying on the discussion in the previous frame, the surface temperature of the fireball actually decreases and then increaser abruptly as a result of processes that are occurring inside the fireball. This produces a do able flash that is characteristic of abrve-ground nuclear events. As indicated in the greph, the first flash is of very short duration ard is followed by a nuch linger flash that contains most of the thermal energy relecsed in the detrnation. This pattern of light intensity is important for interpreting data obcained from satellite optical senso: $s$ used to detect the occurrence of atmospheric nuclear detonations. The emission of other kinds of radiation (e.g., $x$ rays, gamma rays, neutrcns, beta particles) at the time of detoration is less us:ui fo: verification purposes since the atmosphere effectively stops th:- radiation before it can reach remote sensors. 


\section{Physics of Nuclear Explosions: Phenomenology}

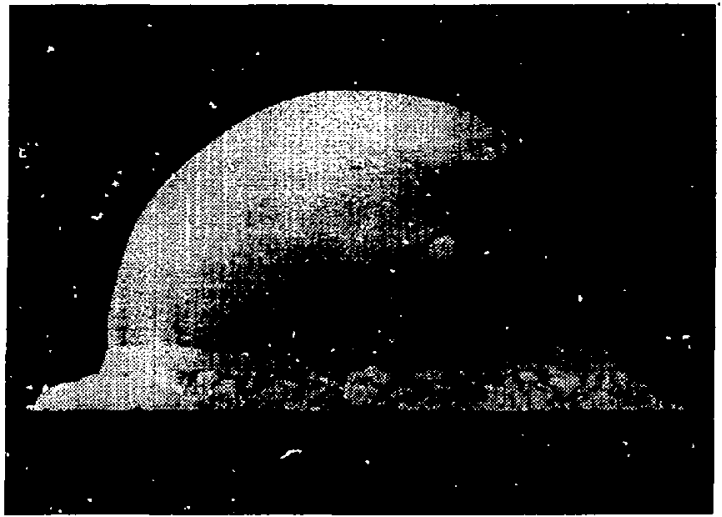

Early-stage detonation of a nuclosi device showing fireball with dirt cloud at base. Photo is the first nucloar tost in Alanogordo, New Moxico. (From Glasstone and Dolan)

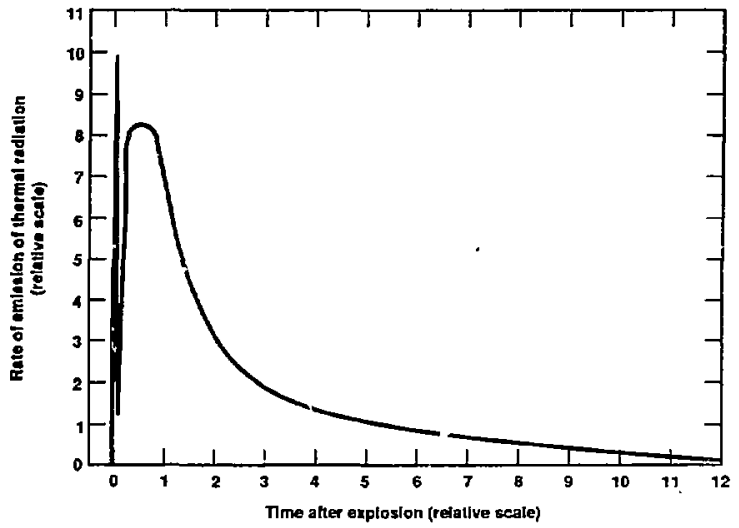

Intensity of sensed ihermal radiation vs time shows the double-flash phenomenon characteristic of atmospheric nuclear tests. (From Glasstone and Dolan) 


\section{Physics of Nuclear Explosions: Phenomenology}

\section{Atmospheric tests: later-stage detonation phenomena for near-surface bursts}

The mushroom-shaped cloud of dust, hot gas, and debris is a late-stage feature of an above-ground, near-surface detonation following the formation and rise of the fireball. The rapidly rising vortex formed by the fireball can inject significant quantities of debris into the upper atmosphere. As the fireball cools, fission products and other vapors condense on soil and debr.s particles that are drawn upward by the rise of the fireball. Heavier particles settle out near the detonation site. However, lighter particles can be carried dowrwind distances of hundreds of kilometers before they settle out. With the aid of particle filters, detection and identification of trace fallout products can be used to corroborate the occurrence of an atmospheric detonation at the surface.

\section{Underwater tests: early- and late-stage detonation phenomena}

Underwater nuclear tests have been used to evaluate naval weapons and strategies. They also represent a potentially less costly means of carrying out a test than emplacement in either a borehole or mined drift. Since they can be carried out in international waters, they may allow the anonymity of the responsible country to be maintained. Shallow underwater tests (less than 200 feet below the surface) produce smaller fireballs for a given yield than atmospheric tests and are therefore less detectable with satellite-based optical sensors. As the fireball gases rise to the surface, water is entrained and may break the surface with fireball remnants at speeds exceeding 200 miles per hour. The resulting cloud and base surge carry fission products with them. Clouds tend to reach lower heights in underwater bursts than in atmospheric bursts, and, owing to the absence of larger fallout particles, the radioactive fallout near the explosion tends to be less than for near-surface atmospheric bursts. Radioactivity in the water near the explosion may be rapidly diluted by furbulent mixing.

Deep underwater tests (approximately 500 feet or more below the surface) may lack a fireball that can be detected by means of satellites equipped with optical sensors. Surface radioactivity also may be very low. 


\section{Physics of Nuclear Explosions: Phenomenclogy}

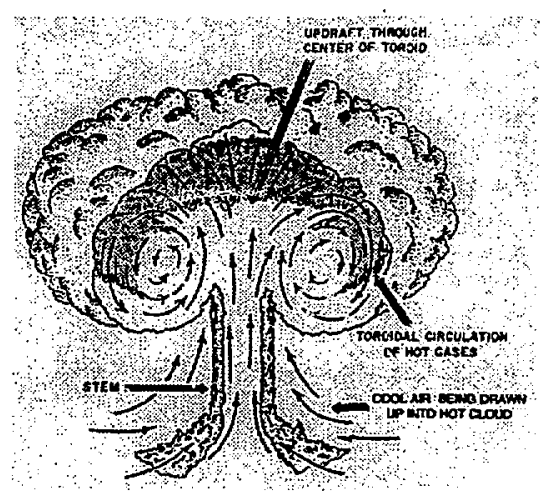

Diagram of rising mushrooin cloud vortex with vertical transport of gases and debris. The cloud rises several tons of thousands of feet into the atmosphere. (From Glasstone and Dolan)

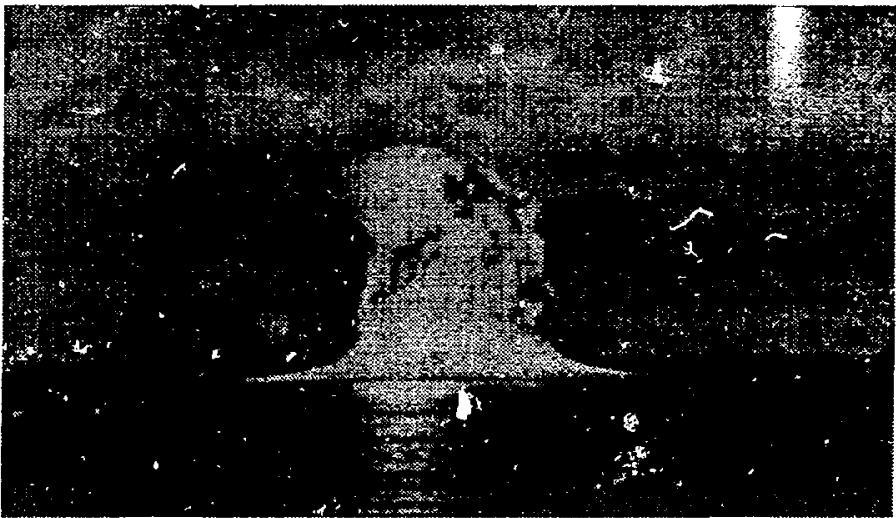

Photo of a spray dome and fireball prodiced by shalbow underwater nuclear test. A deeper underwater axplosion may no1 produce a fireball detectable at the water's surface. (From Glasstone and Dolan? 


\section{High altitude and space tests}

Nuclear tests have taken place at high altitudes (10-250 miles above ground). In the altitude range between 10 and 50 miles, $x$ rays from a detonation produce a large fireball since they will travel greater distances in the thin atmosphere before depositing their energy than they would in the denser atmosphere at the surface. These fireballs may be extremely bright and visible at distances of several hundred miles. In the case of the TEAK event, the fireball and its associated halo caused by excited oxygen atoms was abuut 600 miles in diameter and could be seen from Hawaii 7100 milis away (see figure). Above 50 miles altitude, ionized debris from the device is mainly responsible for the fireball. The Earth's magnetic field begins to exert an influence on fireball formation by ionized debris at this level.

In the case of deep space detonations, there is no material with which the bomb debris and radiation can interact, so optical effects are minimized. However, because of the low to vanishing density of the Earth's atmosphere, $x$-ray and gamma-ray emissions from detonations at very high altitudes and in deep space can tra vel indefinitely before significant absorption and thermalization occur. Thus, very high altitude tests and deep space events can be monitored remotely with the aid of $x$-ray and gamma-ray sensors on orbiting surveillance satellites.

Another feature of high altitude (greater than 20 miles high) nuclear bursts is their potentially disruptive effects on communications and powezgrid tircuits over large areas (millions of square miles). Ionization of the device materials and the surrouriding amosphere produces a rapidly expanding high-temperature plasma around the detonation point. Charge separation between negatively charged frez electrons and the ionized nuclei produces a strong electric field in an extremely short time $\left(10^{-8}\right.$ seconds). .

While atmospheric tests may produce stronger local electromagnetic disturbances, i,igh-altitude tests wili: cause disruption over much greater areas. Ine remote monitoring of electromagnetic pulses is a potentially important $\mathrm{mo}$. $\mathrm{is}$ of detecting the above-ground detonation of a nuclear device. 


\section{Physics of Nuclear Explosions: Phenomenology}

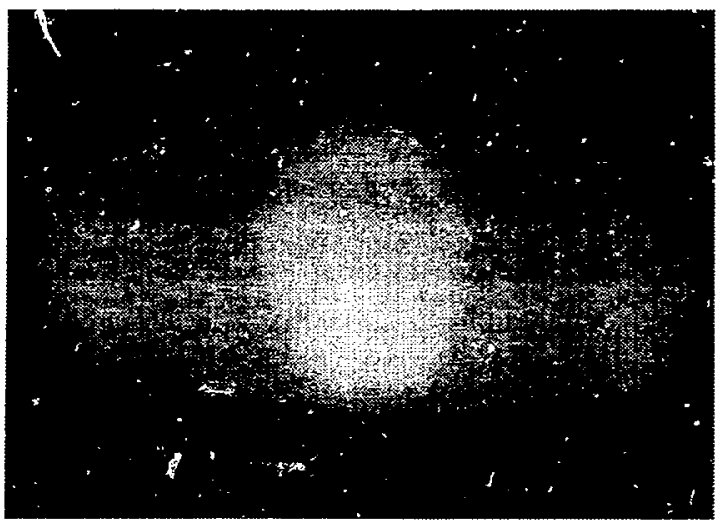

Photo of TEAK experiment during its high-altitude fireball stage. The firoball was easily visible from Hawaĩ 700 miles away. (From Glasstone and Dolan) 


\section{Underground tests: borehole emplacement}

Since the early 1960s, weapons tests with significant nuclear yieids have been conducted underground in the U.S. One mode of emplacement beneath the surface involves boring very large diameler holes to a typical depth of 200 to 700 meters. The depth appropriate for a given yield is governed to some extent by the local geology and overburden required to fully contain the detonation. It has been U.S. experience that if the depth of emplacement is greater than about $107 \times$ (yield in kilotons) ${ }^{1 / 3}$ meters, gases from the experiment are usually contained within the overlying soil and rock. Following emplacement of the device and relevant diagnostic equipment, the hole is plugged and backfilled. Detonation of the device vaporizes significant amounts of the surrounding material. The rock and pore water that is vaporized expands as a gas and forms a growing cavily during the detonation. Following a test, rock and soil overlying a cavity may fall into the cavity and result in the formation of a vertical chimney. If the infall of the overburden occurs all the way to the surface, a surface depression, or crater, results. Stress-induced fracturing and chimney formation may occur for several weeks following a detonation. Local seismic activity associated with the chimney formation process can be used to corroborate the occurrence of an underground nuclear event.

\section{Underground tests: device and diagnostics for a borehole nuclear experiment}

The nuclear device and diagnostic equipment that both momentarily senses and relays data about device performance to the surface may form a downhole package weighing about 100 tons. Cranes and a tower are typically ustd to mate the device and electronics canisters and then lower the package with it associated cabling down the hole. While not a reliable indication of testing activity, the presence of this surface equipment can be significant from a verification perspective. 


\section{Physics of Nuclear Explosions: Test Environments}

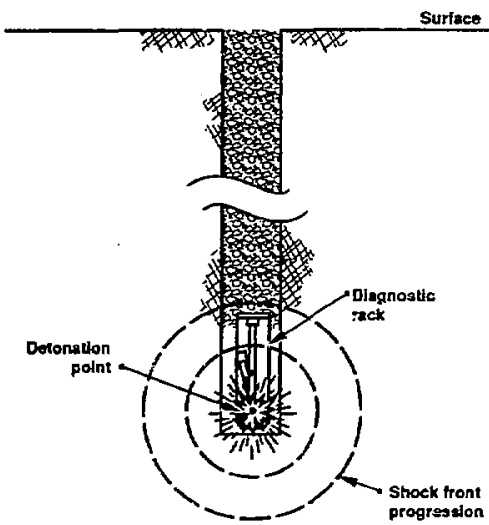

Sketch of borehole emplacement of mated weapons and diagnostics canisters for an underground nuclear test.

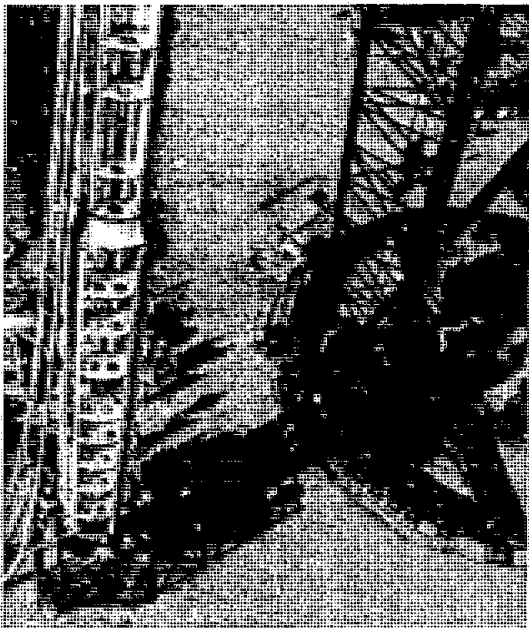

Mated device and diagnostic canisters suspended by crane at the

Nevada Test Site. 


\section{Underground tests: surface facilities and equipment supporting a nuclear device emplaced in a borehole}

Extensive surface facilities and above-ground activity are generally evidicht for non-evasive borehole nuclear tests. In the early stages of preparation for a test, a very large drill rig and its peripheral facilities are present. Closer to the time of the test, a tower or highbay structure standing over the borehole, cranes, cabling, and diagnostic equipment trailers are brought to the site. Because of the complexity of borehole nuclear testing, extensive pre-shot surface activity is typical.

\section{Underground tests: tunnel and mined drift emplacement}

A mine or tunnel system represents an alternative appreach to carrying out underground nurlear tests. Cavities can be mined off main tunnels for emplacement and testing of nuclear devices. A proliferator's testing requirements might be satisfied by a very simple arrangement or, as with U.S. tunnel tests, quite complex.

Most or all of the diagnostic facilities that support a test can be installed in rooms mined off of the nain tunnels. In addition, extremely sophisticated experiments can be canied out in the tunnel mode of operation. The figure illustrates an experiment intended to test the ability of electronic equipment to withstand radiation effects produced by a nuclear explosion. At the end of a long pipe or conduit (at left in figure), a nuclear device is detonated. Prompt radiation from the detonation trayels down the pipe and irradiates equipment that is mounted in test chambers at the other end of the pipe (at right in figure). If left unattenuated, the blast wave created by the detonation would follow some milliseconds behind the arrival of prompt radiatic $n$ and destroy the test chambers. Instead, a rapid closure system (as in the figure) would block the pipe before the blast wave could pass through and reach the test charibers.

An attractive feature of the mining approach for developing nuclear weapons is that excavation of large cavities can be used to partially decouple an explosion from the surrounding rock and therefore reduce the seismic signal strength that a treaty monitoring organization migit detect. Another advantage of mines over borehole emplacement is that satellite monitoring of preparations is more difticult since most of the activity and most of the equipment can be confined to underground tunnels and rooms. Further, other mining activities can be used to cover, to some extent, activity associated with a weapon test. 


\section{Physics of Nuclear Explosions: Test Environments}

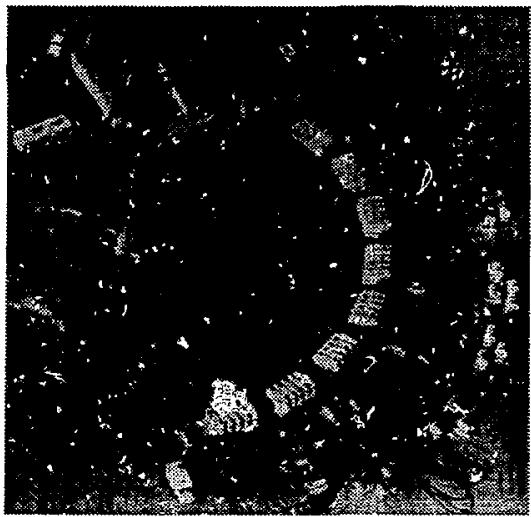

Surface facilities layout of a nonevasive underground test.

Schematic of a tunnel and tast closure system near device (not to scale) at the

Nevada Test Site.

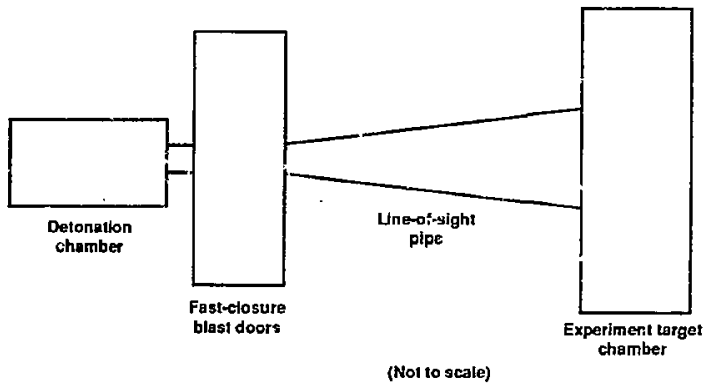




\section{Physics of Nuclear Explosions: Test Environments}

\section{Reusable containment structures for very small nuclear detonations}

Very small nuclear tests (tens to hundreds to perhaps thousands of pounds of nuclear yield) can be completely contained within heavy-walled sieel containers, either above ground (see figure) or buried. A massive metal tank, nicknamed "Jumbo," was temporarily considered for use in the first U.S. nuclear test in 1945 to prevent loss of valuable nuclear material in the event the test resulted in a negligible nuclear yield. The advantage of a containunent structure's reusability may be more than offset by the liability associated with the severe radioactive contamination of the vessel following a single use. 


\section{Physics of Nuclear Explosions: Test Environments}

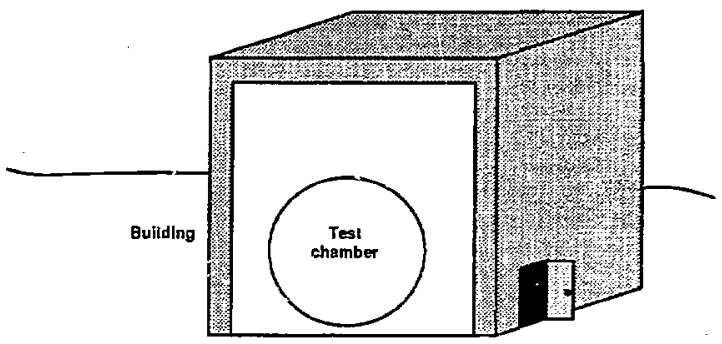

A schematic of reusable contain. ment structure for very small nuclear detonations. (Not to scale.) 


\section{One-point safety experiments for stockpile reliability evaluation}

The safety and reliability of the U.S. nuclear stockpile providss significant motivation for testing. One important safety criterion is that a weapon should always fail to produce a significant nuclear yield in the event that the highexplosive charge is detonated at a single point. This could accidentally happen, for example, from a stray bullet. One-point safely experiments involve the ignition of the high explosive in a nuclear weapon at one point to produce the asymmetrical conditions of implosion that would be characteristic of an accidental event.

\section{Hydrodynamic and very-low-yield hydro-nuclear experiments}

How the high explosive surrounding a pit implodes is critical to evaluating both the reliability and the potential yield of a particular nuclear weapon's design. Thus, much preliminary research can be done on a design: without the need to produce a nuclear yield. A "pin dome" hydrodynamic experiment uses a spherical distribution of pins, or contacts, to electrically sense the nature of the implosion of an inert material into the central void of a highexplosive charge. No nuclear yield is associated with such experiments.

Hydro-nuclear experiments are carried out for similar reasons but involve modification of the fissile component of the device to reduce nuclear yield to almost vanishing levels (e.g., the equivalent of a few hundredths of a pound of TNT). Hydro-nuclear experiments were first carried out in the U.S. during the Eisenhower administration during a moratorium on nuclear testing. 


\section{Physies of Nuclear Explosions: Zero-Yield}

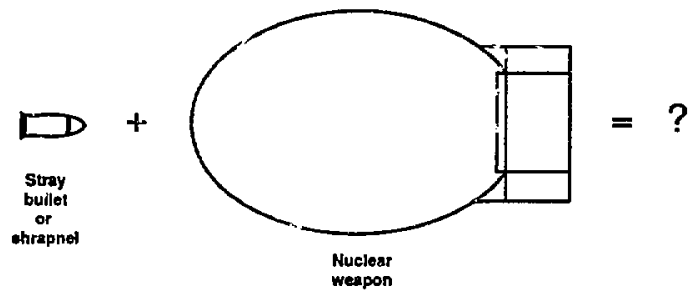

Schematic illustrating the salety question that is addressed by a ono-point safely experiment.

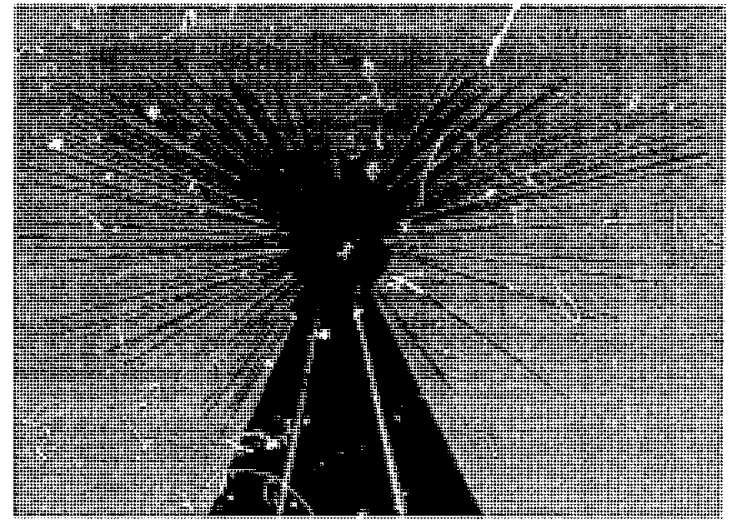

Photo of "pindome" hydrodynamic experiment. 


\section{Other Nuclear Experiments}

\section{Introduction}

Several types of nuclear experiments are not nuclear tests, even though bursts of energy and radiation are produced by either fission or iusion processes. By comparison with the kiloton yields of NTS weapons tests, these experiments involve almost vanishingly stuall releases of energy. These energy releases are carried ott in laboratory facilitie: that are fully reusable (see figure). The unertial confinement fusion experiments are the best examples of this category and often involve international collaborations among courirses that do rot have a nuclear weapons program. Thus, we devote a shor. separate chapter to this category of fission/fusion experiments.

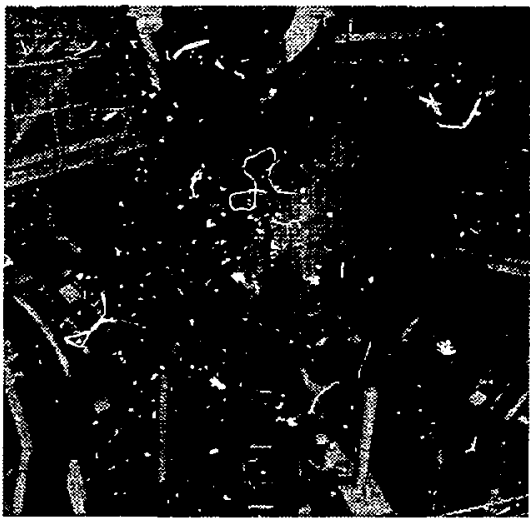

Inertial contine. ment fusion target chamber at Lawrence Livermore National Loboratory. 


\section{Other Nuclear Experiments}

\section{Very-low-yield inertial confinement fusion experiments}

Inertial confinement fusion is one of several kinds of fusion research being being carried out on an international scale for peaceful purposes. The figure shows the processes used in a typical laser-fusion experiment. Neutron counters are used to determine the magnitude of the event so that yields are usually expressed in terms of total neutrons produced rather than an equivalent amount of TNT. The largest output produced to date by the Nova inertial confinement fusion experiment is $10^{13}$ neutrons. In terms of energy released, this is approximately equal to only millionths of a pound of TNT. From a verification perspective, only highly invasive, in-cavity means could be used to monitor such experiments. Remote monitoring of emitted energy (e.g., electromagnetic pulse, seismic waves) would not be possible due to the very small amount of energy released.

\section{The Saturn pulsed-beam fusion experiment}

The U.S. Department of Energy is currently supporting other types of fusion experiments. As an altemative to laser-driven fusion, Sandia National Laboratories is investigating inertial confinement fusion using high-energy charged particle beams (protons, ions, or electrons). A circle of radially oriented beams provides the symmetrical energy distribution needed for implosion of a deuterium-tritium capsule. 


\section{Other Nuclear Experiments}

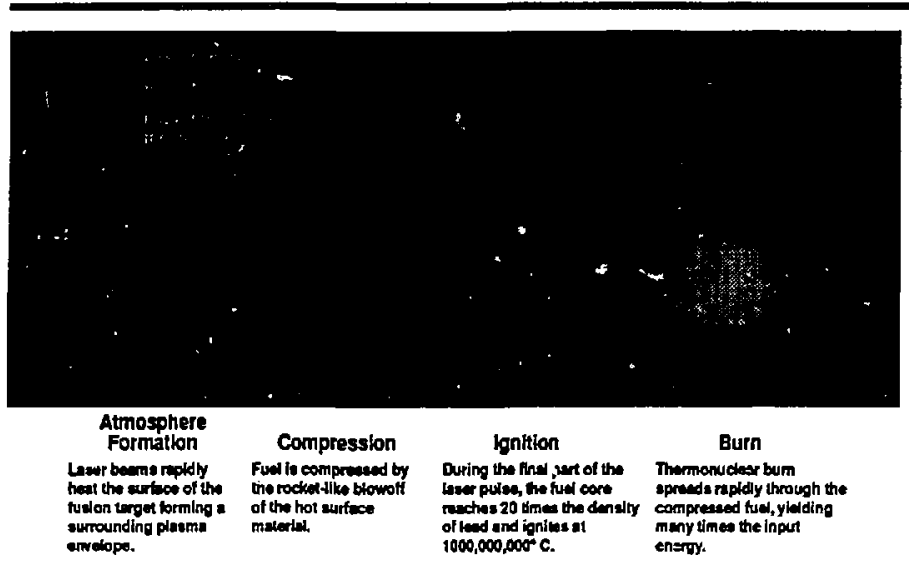

The soncept of inertial continement fusion microsphese deionation by lasers.

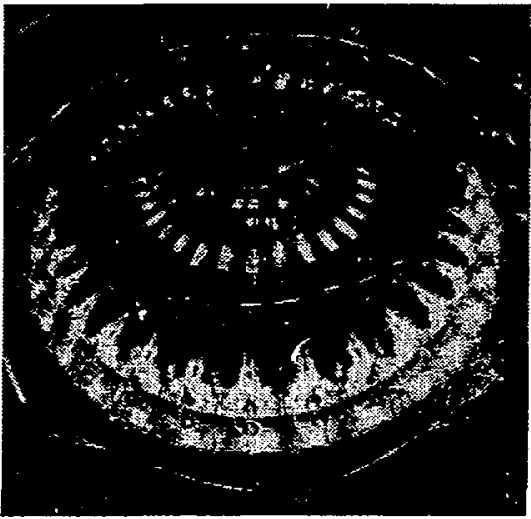

Sanuita Narional Laboratories" Satum electron' ion-beam inertial confinement exporimeni. 


\section{Other Nuclear Experiments}

\section{Pulsed power reactors used for controlled bursts of radiation}

Extremely short and intense bursts of radiation can be produced withwut achieving a supercritical runaway state as opposed to an explosion which producs an intense burst of radiation as a result of ninaway. A pulsed power reactor involves rapidly moving one subcritical mass of a fissile material into the proximity of another subcritical mass to produce a very short-lived, critical arrangement of the two masses. Because of the high speed of one mass relative to the other, the close proximity of the two masses is maintained for only a very small fraction of a second. The arrangement of rapidly moving subcritical masees to produce a burst source is reusable, unlike the mechanism of a nuclear weapon. This specialized type of reactor is a research tool that can be used for such purposes as studying the effects of intense radiation on miniature electronic components. 


\section{Other Nuclear Experimerits}

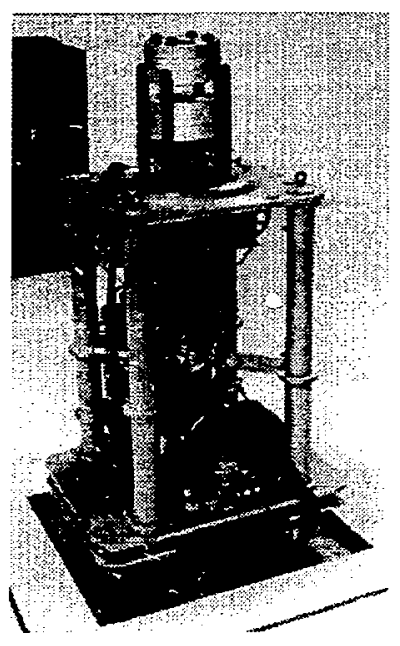

Pulsed power reactors can be s:iall units for table-top experiments. The neuIron pulse may last for only 40 microseconds and yet produce enormous radiation fluxes. 


\section{Introduction}

Because there are a variety of entironments in which a courtry might conduct a nuclear test, many types of tools are required to monitor the occurrence of those tests. Generally, monitoring technologies fall into four general categories:

- Seismic and hydroacoustic tools using various frequencies, waveforms, and data collection methods for monitoring underground and underwater tests. - Electromagnetic, light, and nuclear radiation sensors capable of measuring the spectrum of emissions from tests conducted aboveground, in the atmosphere, and in space.

- Debris sampling to measure nuclear emissions by counting the characteristic fission by-products in the atmosphere, 5 , and water.

- Nuclear weapon diagnostic tools and other intrusive measurement devices to measure the extremely small amounts of evidence from the proposed "permitted experiments" portion of a CTBT.

Following are descriptions of the relevant phenomena, instruments that can be used for measuring and verifying compliance, and ways in which a country may be able to evade detection. The descriptions are grouped according to the environments in wh.ch nuclear tests would be detonated: underground, in the atmosphere, in space, and underwater. Another type of environment, the laboratory, is where permitted experiments would be carried out. 


\section{Monitoring underground nuclear explosions depends upon detecting and identifying their seismic waves}

The primary tools for monitoring underground nuclear tests come from the field of seismology: the study of earthquakes, the generation and propagation of seismic waves through the Earth, and related phenomena. An underground nuclear explosion cteates a hot bubble of vaporized rock a: pressures of several million atmospheres within the first microsecond. The expanding gas creates a cavity, while the shock wave crushes rock as it propagates outward into the surrounding medium. As the strength of the shock wave decays near the explosion, it no longer permanently deforms the medium, and the waves then travel through the Earth as seismic waves. As the seismic waves pass by, the ground motion on the surface can be recorded and used to detect an event and to estimate its size and location.

The figure illustrates the form taken by the seismic waves created by an explosion or earthquake as they travel through the Earth. Body waves are those that pass deep within the earth; surface waves travel along the Earth's surface. When they are recorded at distances greater than about $2000 \mathrm{~km}$, the body and surface waves are known as teleseismic waves. They have the advantage of not requiring instruments near the source, but the distance reduces the amplitude of the waves and limits deteztion capability. Regional waves travel predominately within the crust with higher frequencies, and can be detected typically at distances less than $2000 \mathrm{~km}$. Closer stations normally give larger amplitudes of ground motion and alln $v$ improved detection capability.

\section{Unique characteristics of explosions and earthquakes influence seismic waves from regional and teleseismic distances}

The different source characteristics of explosions and earthquakes influence the amplitudes and frequency content of the different seismic waves arriving at both regional and teleseismic stations. The figure shows examples of these waves measured on instruments sensitive to long period (about 20second) and short period (less than I second) waves at a regional distance. Faulting associated with earthquakes tends to emit a larger proportion of energy in the form of shear waves (also called s-waves) and surface waves than an explosion. In addition, earthquakes have much larger source dimensions. This enhances the longer seismic wavelengths (lower frequencies) compared to explcsions. However, for small earthquakes and explosions, these differences are less pronounced. Discrimination of small earthquakes and explosions is an area of active research. 


\section{Monitoring Tests-Underground}

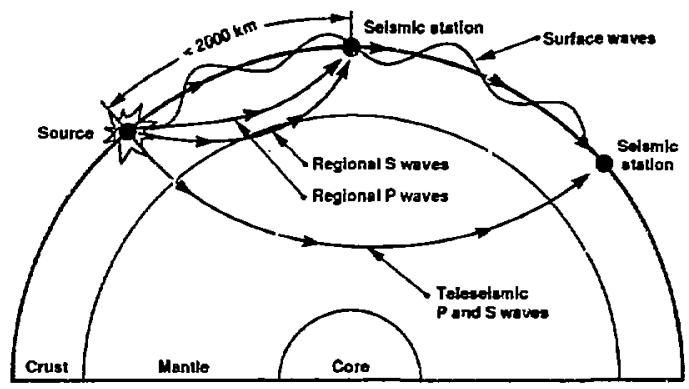

Cross section of earth showing shallow source, bcdy waves traveling trom the earthquake ar explosion to regional and teleseismic distances, and surface waves following the Earth's surface.

\section{(a) Earthquakes}

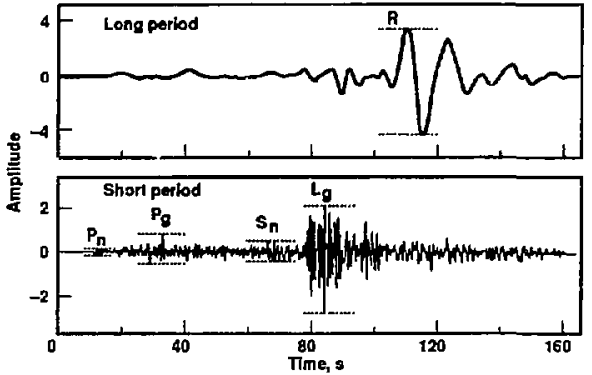

(b) Explosions
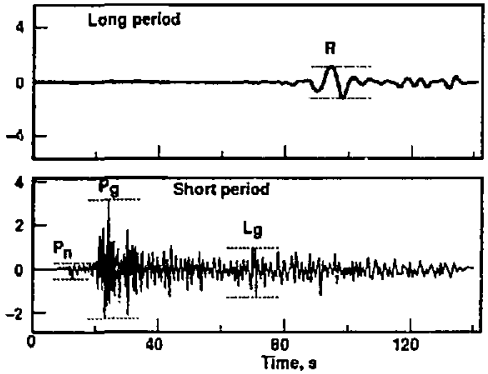

Seismograms from (a) earthquakes and (b) explosions at regional distance. Also illustrated are measurements of the amplit:vde of seismic phases used for magnitude and yield estimates. Compare phase times with figure above. $R=R a y l e i g h$ wave, i.e., a surtace wave. Pn = Regional P-wave that travels just under the Earth's crust. $S n=$ Similar to $P n$, except that it is for a shear wave. $\mathrm{Pg}=$ Regional P-wave that is trapped in the crust. $\mathrm{Lg}=$ Similar to $\mathrm{Pg}$ except that it is for a shear wave. 


\section{Monitoring Tests-Undergruund}

\section{Seismic discriminants exploit differences in source functions}

The unique source characteristics between earthquakes and explosions can be used to construct discriminants. One of the best known discriminants plots tha ratio of shear wave energy $\left(M_{s}\right)$ and compressional wave energy ( $m_{\mathrm{b}}$ i upper left panel of the figure). Explusions have more compressiontalwave energy so they plot above the earthquakes. Other discriminant.s are possible. Note that below $n_{b}=4$ the earthquake and explosion poptulations overlap. Discrimination at low magnitudes is more challenging.

\section{Measurement devices can be set up worldwide for collecting seismic data}

World wide coverage for detection and discrimination requires seismic instrumentation dispersed over the whole globe, each site located and designed to minimize extraneous natural and cultural noise. Station design might incorporate independent power sources to allow operation in remote areas. As the figure illustrates, a station might have a deep borehole to locate the seismic sensor away from surface noise and tampering. After authentication, the data could be relayed via satellite to established data centers for analysis and association with events detected at other independent stations. This analysis and association process has been the basis for technical tests conducted by the Ad Hoc Group of Scientific Experts of the Conference on Disarmament. 


\section{Monitoring Tests-Underground}
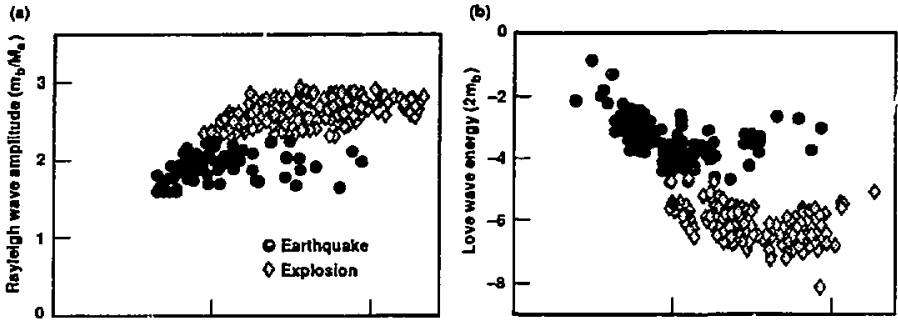

Examples of seis-

(c)
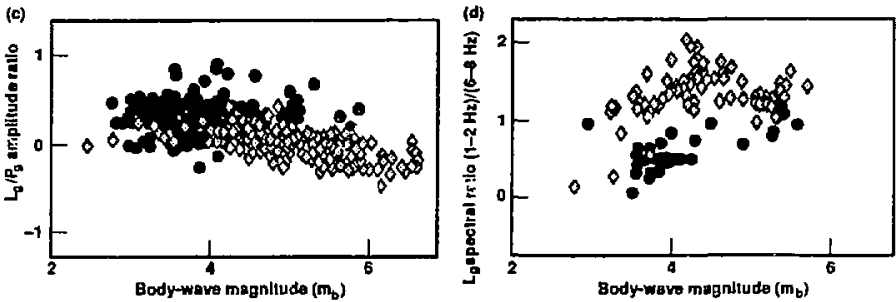

(a)

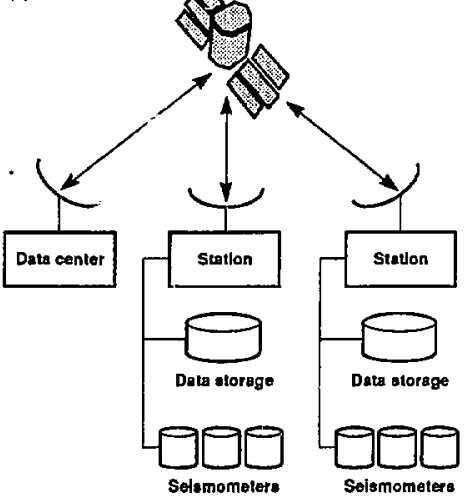

(b)

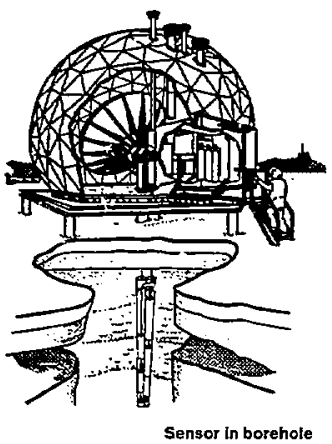

(a) Schematic of data path for transmitting ground motion measudernents to a central recording area. (b) View of example for a remote station. 


\section{Arrays of seismic instruments greatly enhance the detection capability of a seismic station}

Much of the "noise" recorded by a seismometer is unique to the specific location of the instrument, while the signal is much the same at oiher nearby locations. This phenomenon can be exploited by locating several seismometers in an "array" spread over several kilometers. The sigrificance of seismic arrays has been ampiy demonstrated in past nesearch by DOE, ARPA, and AFTAC. In the figure, a mining explosion near $5 t$. Petersburg is shown as recorded at NORESS in Norway using both a single, high-frequency sensor and the composite waveform from the array of sensrors. The array clearly detects an explosion.

\section{One evasion scenario for underground testing is decoupling}

Seismic decoupling was first proposed as an evasion scheme during the Geneva Conference in 1958. The seismic signals emitted by a nuclear explosion in a sufficiently large cavity are much smaller than the same explosion detonated in a conventional underground test. The effect of cavity decoupling has been verified by both the Former Soviet Union and the United States. Observed decoupling factors typically range up to 70 , a reduction in seismic magnitude of roughly 1.8 . A cavity to fully decouple a 1-kiloton explosion must have a $20-\mathrm{m}$ radius. Although this is a large cavity, many cavities have been butlt of this size or even larger, particularly by dissolution mining in salt.

The figure illustrates the range in size of large cavities currently standing and the corresponding fully decoupled nuclear explosion that could be detonated in such a cavity. The largest cavities formed by dissolution minir: could fully decouple explosions up to 260 kilotons. The largest hardrock cavities could fully decouple explosions up to 10 kilotons. 
(c)

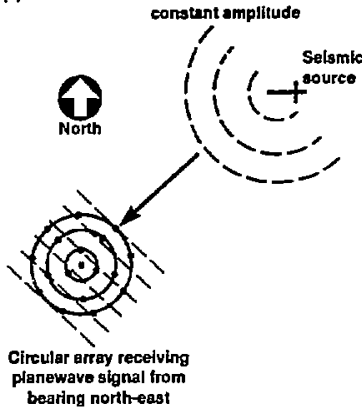

(b)

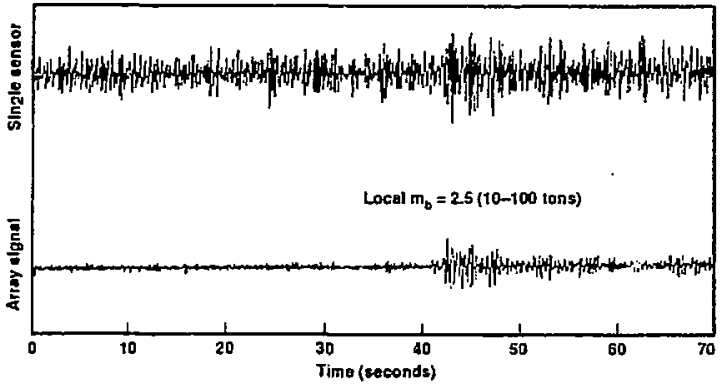

(a) Map view of array of seismometers Lsed for developing composite wavelorms for regional and teleseismic phases. (b) Example of soismic signats from one element and the summed signal from all sensors. Notice that with the array the signal from the Gient is unambiguous, while with the single sensor the event is buried in the noise.

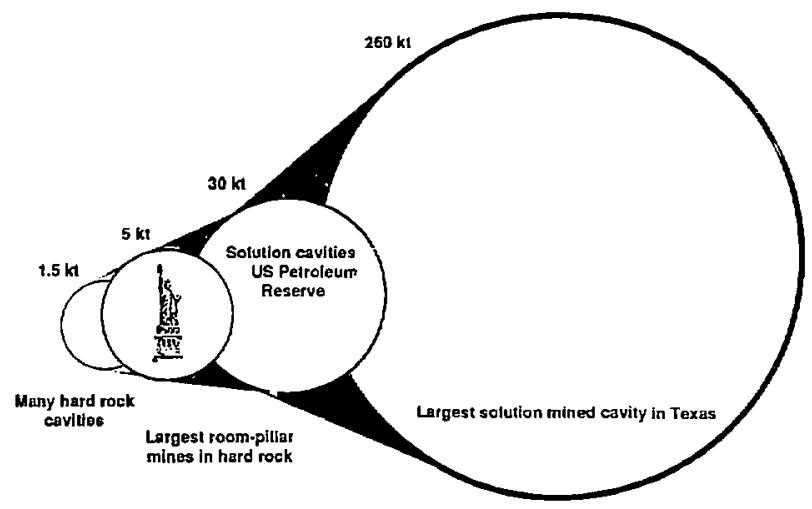

Decoupling, or mutlling, the yield of an explasion is accomplished by emplacing the nuclear experiment within a cavity. 


\section{Monitoring Tests-Underground}

\section{Quarry blasts and chemical explosions present other evasion scenarios}

For detection and discrimination at small magnitudes, chemical explosions used for mining and quarry operations present a formidable challenge. A large chemical explosion can mask a deep, small or larger decoupled underground nuclear explosion. These sites already involve industrial activity, such as massive movement of earth and an extensive infrastructure, which could be tapped for a test. A carefully designed test would not necessarily interrupt nomal operations at a large mine.

Deep mines also introduce the possibility of masking a nuclear test with mine seismicity or rockbursts. Mine seismicity is induced by normal operations. The removal of material within a deep mine, normally deeper than 1 kilometer, causes stresses in tunnel walls. This stress can cause a mine to collapse. However, only a limited number of mining regions around the world fit this profile. A nuclear explr.sion could be made to trigger a large mine collapse or fajluse, which could confuse the ustal discriminants for a nuclear explosion.

\section{The global monitoring system will be required to analyze a large number of events}

Monitoring to a level as low as a few kilotons corresponds to a seismic magnitude of about 3 . The plot shows world-wide earthquake activity of which there are approximately 100,000 per year above magnitude 3 . Not shown are the hundreds of thousands of chemical explosions that are recorded every year from mining operations. Although the vast majority of these events do not exceed magnitude 3 , they are recorded by seismograph stations close to the events. Furthermore, the chernical explosions above magnitude 3 could potentially be used to mask nuclear tests. Clearly the global seismic network will have a massive data handling problem and a potential for recording a large number of ambiguous events. 


\section{Monitoring Tests--Underground}

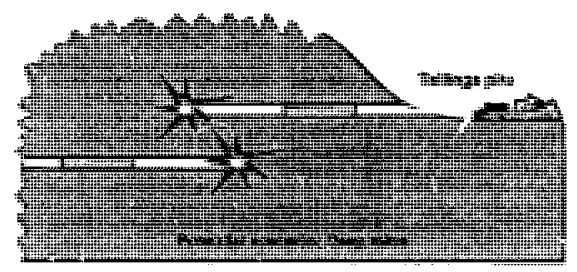

Example svasion scenario: a leginimate, declared explosion in a deep mine used to mask a deeper nuclear test.

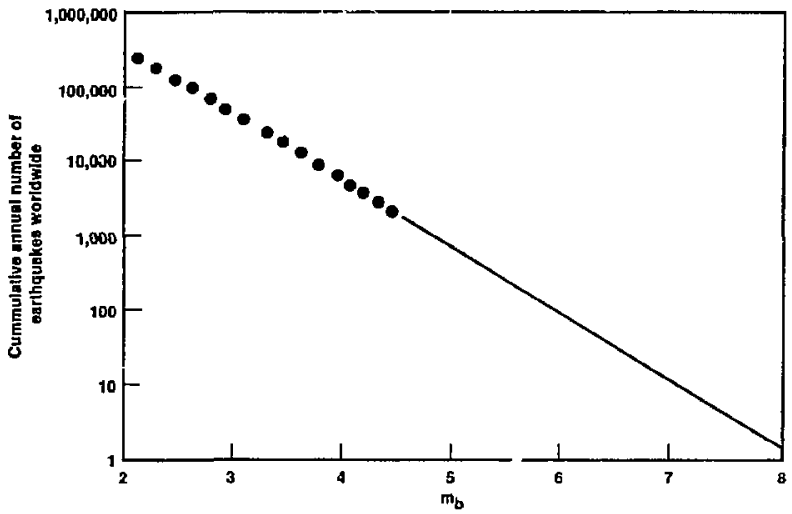

Approximately

120,000 earth.

quakes occur per

yoar abova magni-

tude 2.5. The line

is dotted below

$\mathrm{m}_{\mathrm{b}}=4.5$ because

current global

teleseismic net-

works do not rou-

tinsly record

events below this

level. Note that

this curve does

not include mining

explosions. 


\section{Monitoring Tests-In the Atmospherse}

\section{A nuclear explosion in the atmosphere produces several signals that may be detected remotily}

Atmospheric nuclear testing was cornmonpu:ce in the early years of nuclear weapons developmeni. Since the Limited Test Ban Treaty of 1\%63, the United States and the Former soviet Union have nst conducted any atmospheric nuclear $t \in s t s$. However, the French and Chinese have conducted some atmospheric nuvlear tests since then. Monitoring for tests conducted in the atmosphere poses different problems than for those conducted underground.

As discussed in Chapter 2, an att.uspheric detonation produces a fireball. The fireball is the result of the prompt radiation of the devine depositing its energy in the air surrounding the detonation. This deposition of energy causes the atmosphere to heat up rapidly to create the : : sball. This interaction of the radiation from the detonation and the atmosphere leads to the double flash shown in Chapter 2. Depending on the design of the device, large amounts of electromagnetic radiation may be released, resulting in the so-called electromagnetic pulse (EMP). The debris from the detonation is carried in the wind where it may be detected by radiation and other detectors.

As also discussed in Chapter 2, nuclear explosions in the upper atmosphere differ from ones in the lower atmosphere. High-altitude nuclear tests (between about 15 and $50 \mathrm{~km}$ above ground) result in a much larger, extremely bright fireball duc to the lower air density, which allows the prompt nuclear radiation to travel fartiver brfore being absorbed. At altitudes of about $110 \mathrm{~km}$, no local fireball is created; instead, the debris particles interact with the atmosphere and the geomagnetic field to creatts a visible, highly ionized region in the upper atmosphere. Satellite-based monioring schemes would use electromagnetic and muclear radiation deiectors inr these high-altitude explosions.

\section{Measurement devices to detect an atmospheric nuclear blast fall into two categories, prompt detection and post-explosion detection}

The prompt signatures of a nucledr test include electromagnetic output. Satellite-based infrared, optical, and ul travic!et sensors (i.e., bhangmeters) can effectively detect an atmospheric blast, provided they have a clear view of the detonation. Similarly, the EMP may also be detected from satellitebased detectors.

Detection of the fission products from a nuclear explosion can be accomplisted by sampling air and water. Analysts can use radiation detectors, particularly gamma-say detectors with multichannel analyzers, to identify characteristic gamma-ray energies associated with specific fission product isotopes. Chemical analyses of samples can also be performed. Life forms known to accumulate specific radionuclides (e.g., marine plankton) can also be collected and analyzed. 


\section{Monitoring Tests-In the Atmosphere}

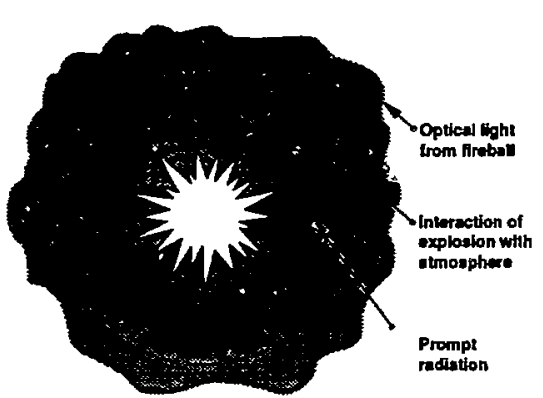

Diagram showing prompl radiation, mostly $x$ rays, heating the atmosphere to produce the optical signal.
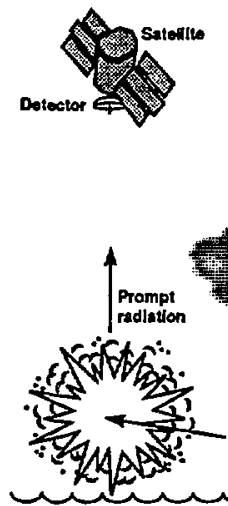

ifta:

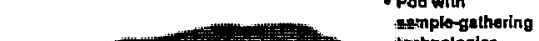
thologles

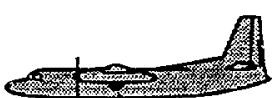

Pod with .

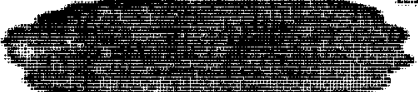

man

Post blast debris

Mind direction

Nuclear explosion

Diagram of

nuclear explosion

at sea with optical

signal shown propagating to a satellite and debris going downwind to an airplane. The déris cloud can travel thousarids of kilometers. 


\section{Monitoring Tests-In the Atmosphere}

\section{An atmospheric nuclear explosion is difficult but not impossible to hide}

Evading prompt detection of an atmospheric nuclear test is probably best accomplished in an extremely isolated region of a continent or in the open ccean during dense cloud cover and at relatively low altitude. A nuclear device can be designed to minimize radioactive debris, although a substantial amount would still be produced. Detection of fission products is irrefutable evidence that a nuclear explosion has occurred. A potential evader willing to accept the high risk of ultimate deter dion would probably carry out the test at sea and focus on evading prompt detection of the blast with hope that delayed detection from the fallout would not be attribulable to a particular nation.

\section{Several non-nuclear sources can produce some signals similar to nuclear explosions}

Similar to nuclear explosions, ccnventional explosions in the atmosphere produce electromagnetic energy such as thermal radiation, visible radiation, ultraviolet radiation, radio frequency energy, and microwave energy. However, the intensity of large conventional explusion electromagnetic energy is, for most frequencies, orders of magnitude less than even a small nuclear explosion. Large lightning bolts and human-generated broadcasting activity can produce EMP-jike signals. A nuclear power-plant accident can produce similar or greater levels of nuclear fallout; however, analysis of the fallout constituents easily differentiates a nuclear explosive source from a nuclear power-plant source. There is no plausible non-nuclear atmospheric source of intense nuclear radiation such as gamma rays, neuttons, and neutriros, or of high-energy $x$ rays. In the absence of such unique signatures, positive identification of an suclear detonation is likely to requine the observation of several signatures. 


\section{Monitoring Tests-In the Atmosphere}

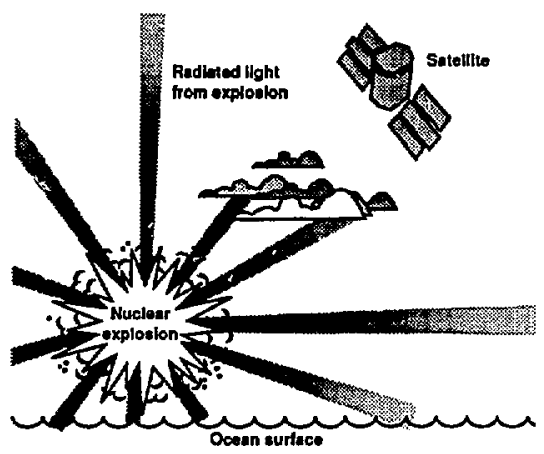

Diagram of ocoan burst under heavy clouds blocking

light to satellite.

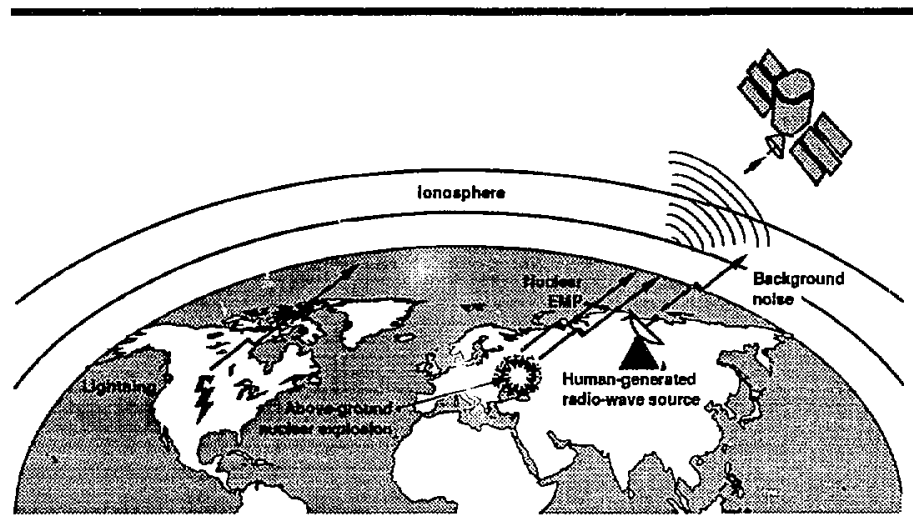

Sketch of globe showing lightning bolts and ather non-nuelear sources of signals. 


\section{Monitoring Tests-In the Atmosphere}

\section{Atmospheric and shallowly buried explosions can create disturbances that propagate through the atmosphere}

An explosion that is detonated in the atmosphere or is shallowly buried releases significant sound (i.e., acoustic) energy into the atmosphere. This energy can travel through the atmosphere for thousands of kilometers where it can be detected with a low-frequency microphone array. This detection technique is known as infrasound. In addition, the acoustic pulse perturbs the ionosphere above the explosion, which creates a wave that can be detected several thousand kilometers distant. 


\section{Monitoring Tests-In the Atmosphere}

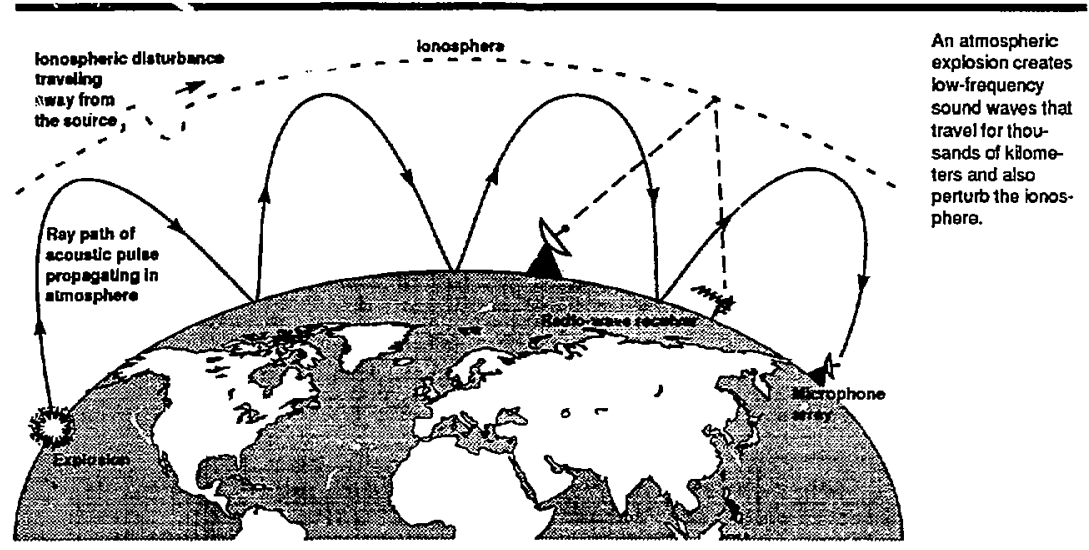




\section{Monitoring Tests-in Space}

\section{Measurement devices to detect a deep space nuclear blast must rely solely on the detection of nuclear radiation}

As discussed in chapter 2 , in deep space there is no surrounding matter with which the bomb's radiation and debris can interact. Therefore, the radiation can travel significant distances. Deep space monitoring is accomplished from satellites with outward-looking radiation sensors.

\section{Evasion in deep space is feasible although it requires aerospace technology}

The figure shows a potential evasion scenario. In this case the evader launches the rocket into the Earth's orbit around the sun and then waits a few months to detonate the explosicn on the opposite side of the sun, which would shield the signals from satellite detector systems that are in orbit around the earth.

Although such a scenario is teasible, a deep space nuclear test presents a number of significant risks and substantial technological difficulties that must be accepted by a potential evader. For one, the rocket carrying the testing payload is easily detected during launch. Any unpublicized and uninspected rocket leaving earth orbit would be suspicious. Furthermore, a catastrophic rocket failure could widely scatter nuclear weapon materials. The technology required for a deep space test is substantial and probably eliminates this as an option for many devel.sping nations at this time. 


\section{Monitoring Tests—In Space}

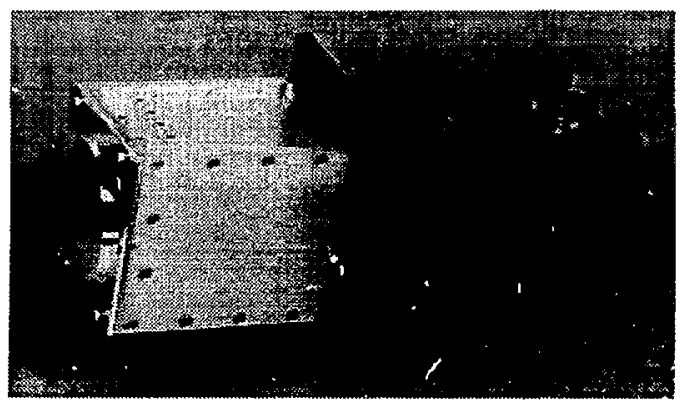

Photo of a DOEdeveloped nuclear radiation sensor. This is an example of the type of satellite-based instrumentation that could be used for deep space monitoring.

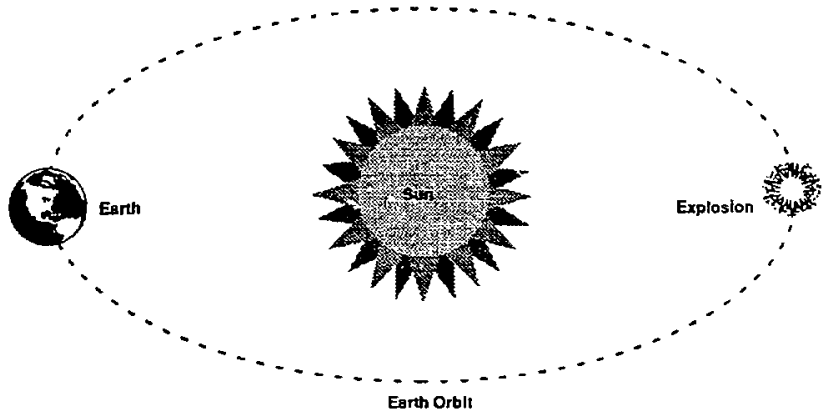

behind the sun. 


\section{Deep underwater explosions have distinctive features as recorded by remote monitoring systems}

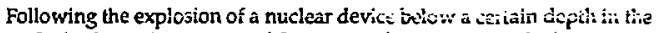
ocean, the hydrostatic pressure of the water column contains the hot gases of the explosion within a bubble, which oscillates up to three times before collapsing. As the expanding hot gas drives the water outward, the pressure drops inside the bubble. The momentum of the water continues the expansion of the bubble beyond the point where the pressure in the bubble equals the ambient hydrostatic pressure. The bubble then collapses, compressing the gas to a high pressure, and the cycle continues. The bubble also rises in the water column as it oscillates, since it is less dense than the surrounding water. As the bubble oscillates, it generates a series of propagating pressure pulses ("the bubble pulse") that are characteristic of an explosion.

Above a certain depth, the bubble vents immediately to the atmosphere. The explosive energy largely decouples from the water if the device is detonated on or above the suriace. Although the hydroacoustic signal can still travel thousands of kilometers, in this case the signal lacks a distinctive bubble pulse and is considerably weaker.

\section{Long-range sound propagation in the oceans can be extremely efficient, especially at frequencies below $200 \mathrm{~Hz}$}

The temperatures and pressures of the oceans cause differences in sound speed: typically high sound speeds are at the surface, declining to a minimum at depths of 500 to 1500 meters, then increasing toward the sea floor. This sound velocity profile (SVP) acts as a lens that channels sound energy toward the point of minimum velocity (the sound channe! axis). The resulting wave guide, called the SOFAK thannel, leads to efficient propagation, since sound energy is bent toward the axis, away from the sea floor and ocean surface, thus limiting attenuation.

The coupling of sound energy from a nuclear detonation into the SOFAR channel depends on the location of the device, the depth and SVP of the water column locally, and, for shallow-water locations, the characteristics of the SVP from shallow water out into the deep ocean. Efficient propagation through the deep oceans depends on the existence of a tree acoustic path (i.e., no blockage by continents, islands, or seamounts). 


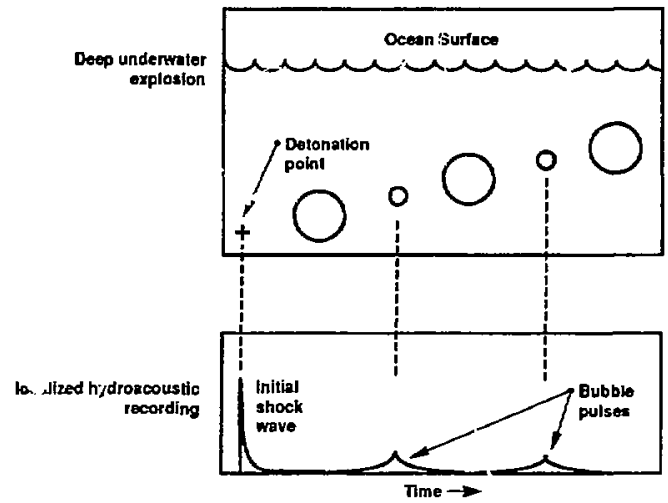

Bubble puise generation. The oscillation of the bubble produces a distinctive signal on remate hydro. acoustic and seismic monitoring stations.

(घ)

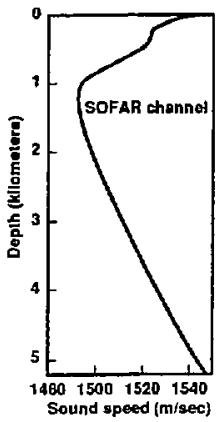

(b)

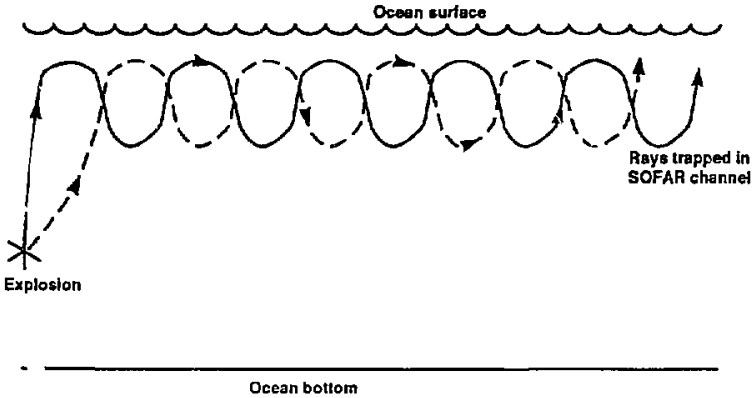

Long-distance measurements are possible because the SOFAR channel causes sound wayes to be (rapped in it. (a) A representative sound velocity profile in the Atlantic ocean. (b) Corresponding ray diagram. 


\section{Fixed sensor systems may be used to msnitor the oceans}

Hydrophones, relatively inexpensive pressure measuring devices, respond to the passage of acoustic waves in the ocean. Individual hydrophones respond equally well to pressure waves traveling in all directions. In order to sense the direction of wave travel and to suppress sensitivity to noise, hydrophones are often ganged into arrays (some with hundreds of individual hudrophones). Permanent vertical hydrophone arrays are anchored to the sea floor by a mass and are stretched out on a cable to a subsurface float. Horizontal arrays lie directly on the sea floor. Data may be transmitted to shore by cable (which may bring power to the array), or it may be stored locally in conjunction with an onboard event-detecticn computer.

Ocean-bottom seismometers are stationary geophones in watertight pressure housings having internal electronics and power sources and externally mounted hydrophones. Their principal advantage is direct observation of both hydroacoustic and seismic signals. Existing systems are mostly researchoriented and are deployed temporatily.

The stationary oceanic sensor systems having the least noise are sea-floor borehole seismometers. These systems are emplaced in drillholes in hard rock beneath the soft sea floor sediment layers and are probably best suited for monitoring detorations on the continents. The principal disadvantages of seafloor borehole seismometers are the high cost and logistical difficulty of drilling boreholes and emplacing the sensors.

\section{Many non-nuclear undersea sources emit significant acoustic signals}

One source of false alarms is chenical explosions at sea, such as detonation of depth charges during naval exercises. Oil exploration ships aiso use arrays of airguns whose acoustic signals are measurable at great range.

Undersea earthquakes can produce large hydroacoustic signatures (T phases) that tend to be long-duration signals, quite unlike the short-duration signals expected for direct observations of the nuclear shock wave. Discrimination of undersea earthquakes is aided by their occurrence along well-defined, tectonic plate boundaries and by the production of seismic body waves. The signature for surface decoupled detonations is not directly known, and the signals from events that are topographically shadowed could have longer duration. Undersea volcanic explosions nay produce a bubble pulse; however, details are unknown.

Other sources of significant acoustic signals in the very low frequency band are ships and whales. Ships emit narrowband signals generated by their rotating power plant machinery. Whales produce loud transients, but have well-defined signatures that are easily discriminated by spectrograms; however, some species produce periodic pulses that conceivably could be confused with a bubble pulse. 


\section{Monitoring Tests-Underwater}

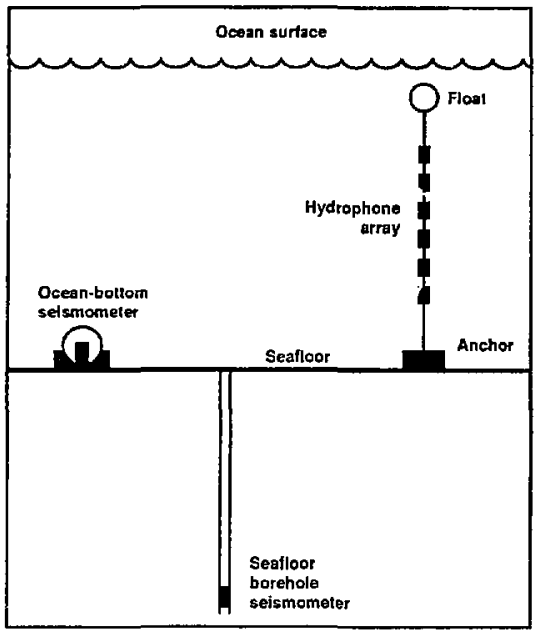

Diagrams of an ocean-bottom seismomeler. borehole seismometer beneath the ocean floor. and a hydrophone array.

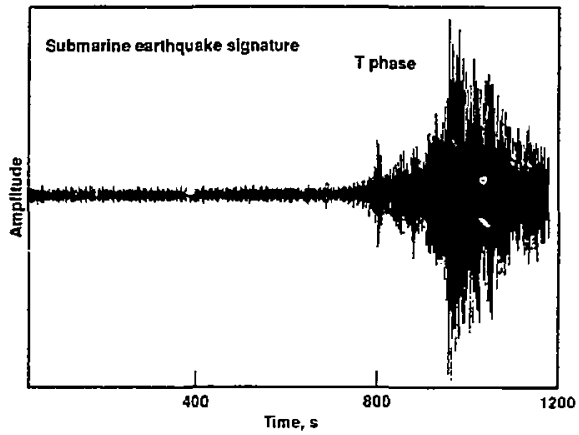

Example hydroacoustic signal showing a

T-phase. 


\section{Monitoring Tests-Permitted Experiments}

\section{Monitoring permitted experiments presents a challenge}

Generally, permitted experiments refer to that class of activities that involve the explosive release of nuclear energy that would be allowed under a CTB. Primarily, permitted experiments fall into two types: (1) those that would be carried out in a reusable facility, and (2) those that would be carried ouf underground in a configuration similar to traditional nuclear tests. Nuclear yields of such tests are thought to be on the order of pounds to tons.

Monitoring such experiments presents several challenges. Among them is the fact that the signals from these detonations are small and unlikely to be detected by global monitoring systems. This fact in turn requires that permitted experiments be declared and available for on-site monitoring if strict verification of adherence to the treaty terms is required. An additional challenge is that, once on site, the monitoring team is faced with obtaining measurements that can separate the nuclear from the chemical yield (see figure). The design of such monitoring systems is an area of active research. 


\section{Monitoring Tests-Permitted Experiments}

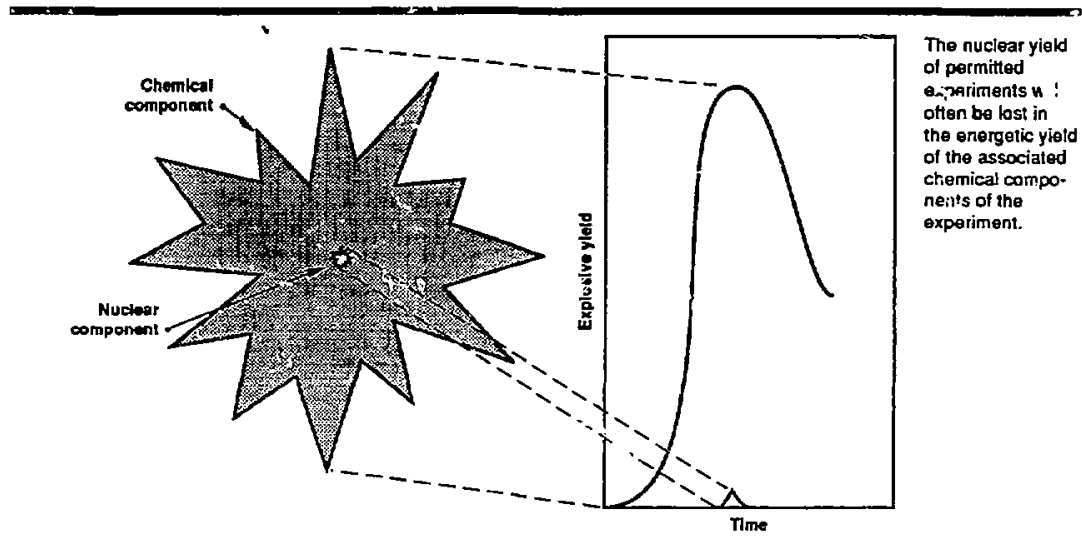




\section{On-site Inspections}

\section{Introduction}

Early CTB discussions were often unsuccessful because of issues related to on-site inspections. Sirce the early efforts, many treaties (see table) have made provisions for inspection tzams to make on-site measurements as part of the verification regime. For example, the Threshold Test Ban Treaty's protocol has a provision for teams $t o$ go to the testing site in the host country, take measurements at the site of the explosion, and operate seismograph stations to verify compliance with the Treaty. A Comprehensive Test Ban (CTB) Treaty could also involve challenge inspection: inspections were discussed during the original trilat=ral CTB talks in the late 1970s, which were never completed.

Recently, the Cherrical Weapons Convention was negotiated in the Conference on Disarmament. Its on-site inspection (OSI) provisions also could serve as a model for the CTB talks.

Treaty

Non-Proliferation Treaty

Threshold Test Ban Treaty

Peaceful Nuclear Explosions Trealy

Intermediate-Range Nuclear Forces Treaty

Conventional Forces in Europe Treaty

Strategic Amrs Feduction Treaty

Chemical Weapons Converition
Date Signed

July 1.1968

July 3, 1974

May 28, 1976

December 8, 1987

November 18,1990

July 31,1991

September 3, 1992 


\section{On-site Inspections}

\section{Clandestine tests are not announced and are unlikely to show surface activities normally associated with a test}

When we think of a nuclear test, many of us thirk of the bypical workings for a vertical test at the Nevada Test Site. These include the cables hid out on the ground, the large drill rigs, and the towers near the emplacement hole. Usually, the desert floor is scraped off to form a hard pack surface for people and machines to move atound easily. Before the shot, trailers are set up near the emplaciment that contain equipment to record the diagnostic information generated when the device explodes. All of these activities are easily observed and identified from overhead imagery.

\section{A determined evader could use legitimate operations to hide ruclear testing activities}

If a country were plasining to evade the Tresty, it is unlikely that they would chose to carry out the test in an isolated desert valley such as the Nevada Test Site. A more likely scenario would be to cover up the test preparations with nearby legal activity. An ideal place to do this is in a mining region. In a deep mine (a in figure), there are likely to be many underground tunnels. The drilling and excavation including the spoils could be totally hidden underground. In the case of an active quarry ( $b$ in figure), piles of gravel and rubble are part of the operations as is drilling for setting charges. In both cases a legitimate chemical explosion could be used to mask the seismic signal from the evasively tested device. If a nuclear test is buried deep enough, no surface crater forms at the surface. For example at ihe Nevada Test Site, shots in Rainier Mesa almost never form craters at the surface. If a device is evasively tested in this manner, no unambiguous surface expression exists that is easily observed from overhead imagery.

Other evasion scenarios might include shooting in oil or geothermal fields where drilling is commonplace. Constructing a huge structure over the surface preparations such as a silo to hide the operations from overhead imagery is another approach. 


\section{On-site Inspections}

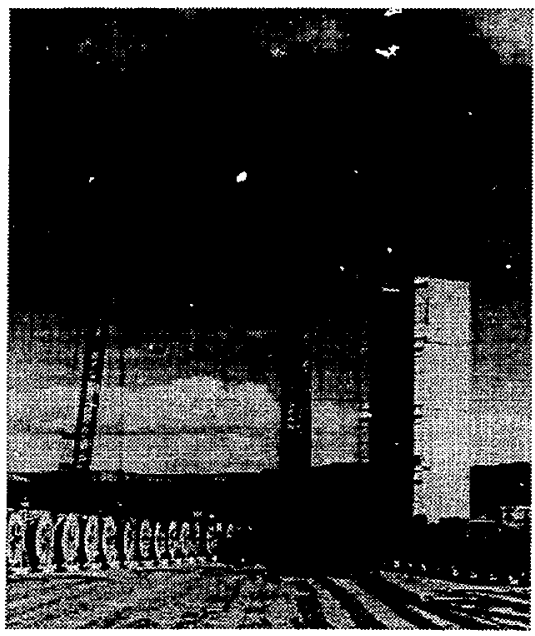

Preparations tor a nuclear test at Yucca Flat at the Nevada Test Site.

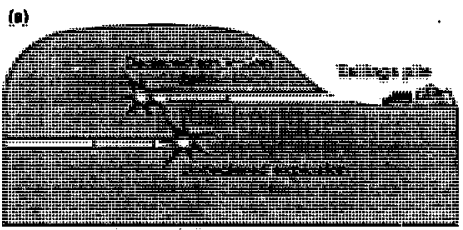

(b)

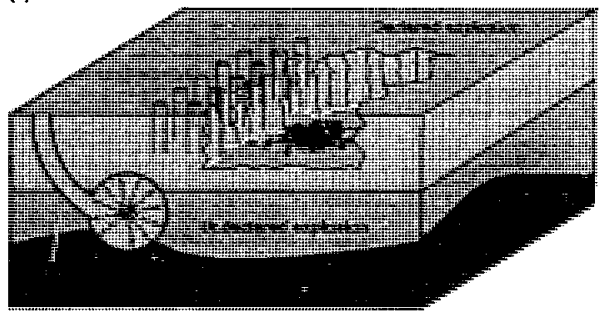

Two evasion scenarios. (a) Cross section of a deep mine showing a declared explosion (above) and the undeclared, clandestine explosion (bolow). (b) Cross section of a quarry blast with the nearby clandestine explosion. 


\section{On-site Inspections}

\section{Nuclear explosions react with the emplacement environment to create residual effects}

Underground nuclear explosions generate prompt phenomena, such as seismic and electromagnetic waves, that have been discussed in previous chaplers. These prompt phenomena are useful for monitoring of declared events for on-site inspections (OSIs) for confidence building. For OSIs after the fact, the detection systems must be sensitive to the residual effects shown in the figure. Upon detonation a spherical region of rock surrounding the device is vaporized. The rock beyond this region is crushed by the shock wave. As the shock wave recedes, the cavity begins to collapse, forming a rubble zone that grows toward the surface. If the shot is buried deep enough, or in hard rock, the rubble zone will not extend all the way to the surface to form the characteristic surface craters observed at Yucca Flat at the Nevada Test Site. Also immediately after the detonation, radicactive gasses are released into the underground envirosment and start to migrate a way from the detonation point, and displaced ground water begins to migrate back into the region. Aftershocks associated with rubble zone formation and local stress relaxation begin to occur.

\section{The OSI process will involve narrowing the search radius}

OSls will be triggered by a detection of an event by one of the remote. continuously operating, monitoring systems. This could be a seismic or satellite system. All technical detection systems have a location accuracy. In the case of a seismic station, the accuracy is on the order of 5 to $50 \mathrm{~km}$ depending where in the world the event took place. If a decision is made to inspect a par. Icular event, a series of searches of decteasing areas will need to be carried out. For discussion purposes, we have named these in the figure and have called out what techniques will be useful at each stage. At each point along the way, the OSI team will need to decide which areas to concentrate on as shown in the transition from step 2 to 3. 


\section{On-site Inspections}

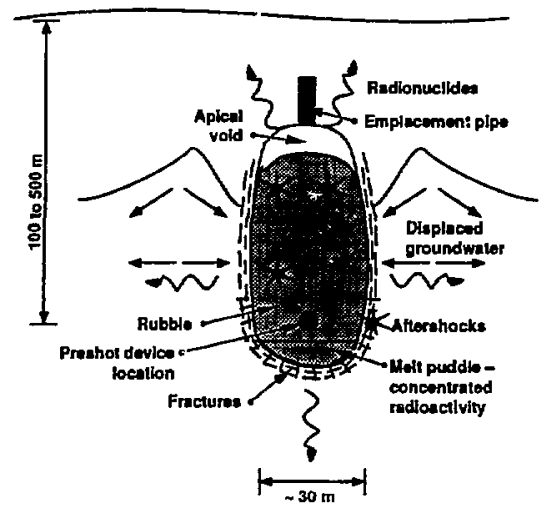

Cross section of earth showing residual effects for an underground nuclear explosion.

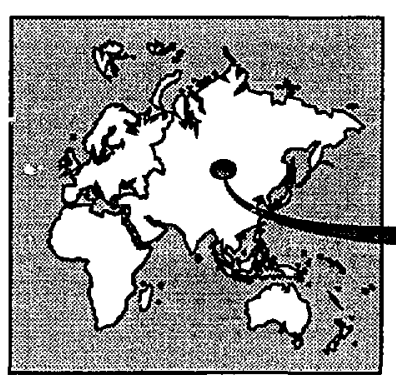

1) Romple ovent delection

- National tochnical means

- Intalligenca
2) Wide area

search

- Seisnic

- Ovehead imagery
Schematic diagram showing the sciles at which OSIs will operate.
3) Local Arat Inveatlgation

- Walk

- Soismic

- Gas Sampling

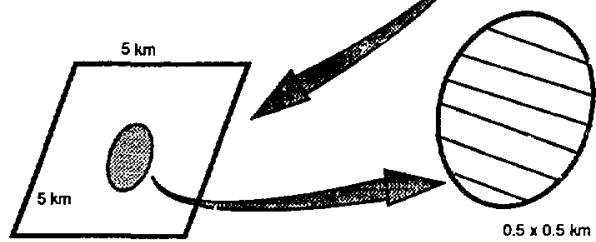

4) Dotailed investigation

- Geophysical sounding

- Seismic

- Electrical 


\section{On-site Inspections}

\section{Radioactive gasses released by an underground nuclear explosion will be transported to the surface}

Krypton-85, Argon-37, tritium, and isotopes of Xenon are released into the underground environment after an underground nuclear explosion. Krypton-85 has a half-life of 10.8 years and is a reaction product of the explosion. It is also produced in nuclear power reactors. Argon-37 has a half-life of 35 days and is a product of the intcraction of the explosion and the surrounding geologic material. The isotopes of xenon have half-lives of a few days. Detection of Argon-37 or radioactivt enon at a site is almost always conclusive evidence of a recent nuclear explosion.

Gas migrates to the surface through fractures in the rock and its inherent permeability. Atmospheric pressure changes actually pump the gas from the ground. Sampling for gas should be done during atmospheric pressurc lows to ensure that gas is flowing out of the ground. Time for gases to reach the surface will depend on the local geology and success of containment efforts. It could range from minutes to several months.

\section{A radioactive gas sampling system could easily be designed to fit into vehicle the size of a van or smaller}

Technology for sampling and detecting radioactive gases was developed for the proposed CTB in the late 1970s. Today's technology will be based on the same principles but be much smaller and lighter. Samples would be gathered by filling an evacuated bottle with soil gas. The gas could be from a probe driven into the ground or collected under a tarp. The gas would be released into a separation trap to remove all but the gases of interest. This step requires refrigeration. Then the gas would be transferred to a counting chamber where the actual amount of the radioactive gases would measured.

The system needs to be able to analyze samples rapidly in the field so that further samples can be taken near any location that seems to show a positive signal. 


\section{On-site Inspections}

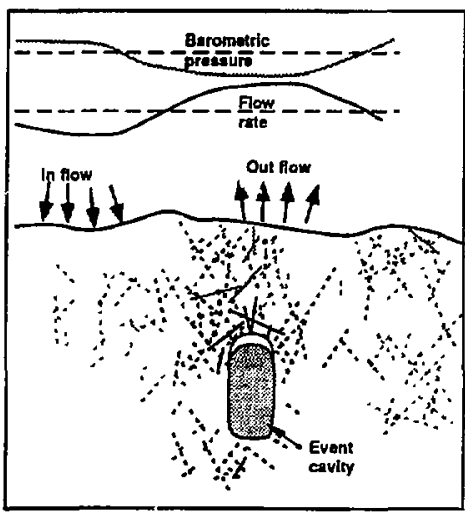

Phenomenology of radioactive gas transport to the surface.

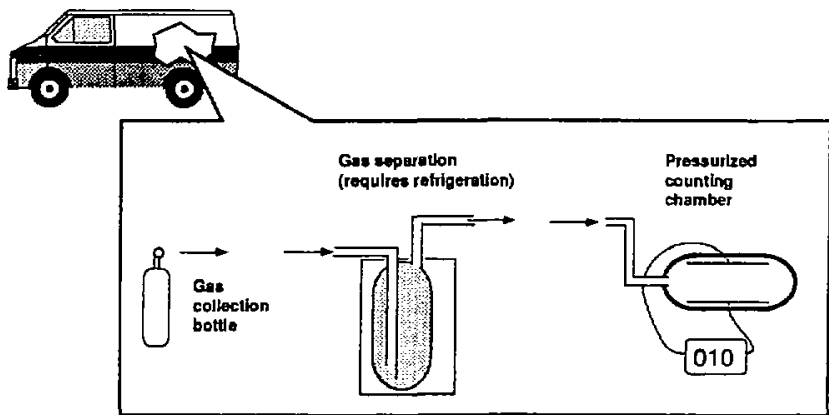

Schematic diagram of the elo ments of a gas sampling and analysis system. 


\section{Local seismic networks may detect aftershocks for months after an underground nuclear explosion or earthquake}

The relaxation of stress and other factors after an earthquake or underground nuclear explosion will produce aftershocks that will be observable for several months after an event. Manv hundreds to thousands may occur. Aftershocks from iarge earthquakes may occur for more than a year after the event. Aftershocks from earthquakes tend to be distributed along planes that define the fault surface. The aftershocks following a shallow earthquake can be quite deep, greater that $10 \mathrm{~km}$. In contrast, aftershocks from nuclear explosions tend to be spherically distributed around the detonation point of the explosion and in general are shallower than earthquake aftershocks. A possible exception is when the nuclear explosion has a significant tectonic release component (i.e., the explosion could release some earthquake energy). In this case in addition to spherically distributed aftershocks, some aftershocks could also be distributed along in plane.

\section{A typical aftershock detection system consists of a number of remote stations that transmit their data to à central site}

A typical aftershock detection system could consist of approximately 16 remote stations that have the ability to record data locally or transmit data to a central site. Current systems use line-of-site radios, but future systems may use satellite links which should allow transmission of the data to a field work site er an out-of-country site. The central recording station is primarily a computer connected to the means to receive the data from the remote stations. The central computer should include enough analysis capability to determine event locations in the field so that station locations can be moved to target specific areas of interest. 


\section{On-site Inspections}

(D)

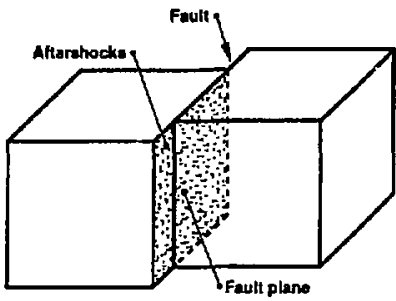

Afterahoek dletributton trom an aerhquate (b)

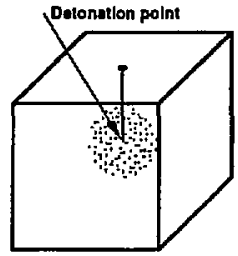

Aftershock distribution hem $\mathrm{n}$ underground explosion

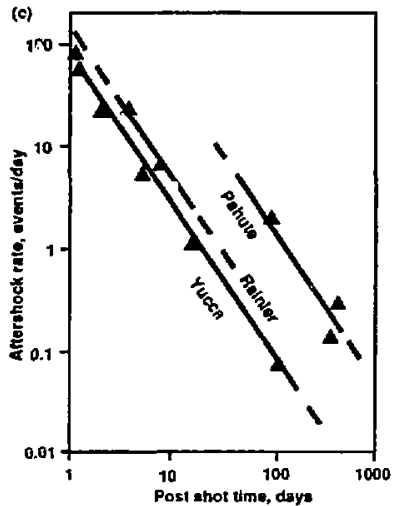

Figures showing distribution of aftershocks around a nuclea-explosion and earthquake and the aftershock production rates for Nevada Test Site nuclear explosions at various locations.

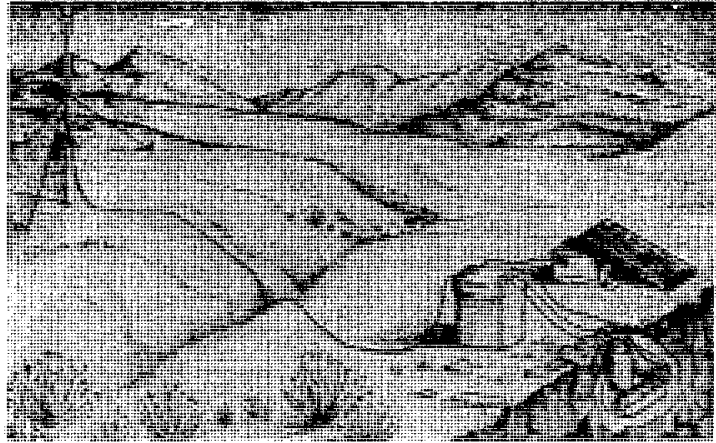

Remote element of an atiershock detection system. The remote site would have buried sensors, a power source, and a dala transmission system. A central recording station, housed in a small trailer, would include data archive and analysis capabiliny. 


\section{In some cases geophysical sounding could be used to confirm the existence of the rubble zone}

The rubble zone from the explosion and void above $\mathrm{jt}$ are appropriate targets for an OSI of underground tests. These features are evidenced as changes in the properties of the geologic material. Under the proper circumstances, it is possible to locate the rubble zone using geophysical techniques such as direct-current resistivity imaging or seismic reflection imaging (figures $a$ and $b$, respectively). In both these techniques, energy is introduced into the ground. The energy propagates through the ground and is perturbed by variations in underground structure. These variations can be sensed by receivers on the surface. These techniques are sujtable for searches only when the inspection team has reason to investigate a certain area more fully.

\section{In some geologic environments, detecting the rubble zone may be impossible because of geologic clutter}

The figure (a) shows a rubble zone as in the previous figure. The seismic or electrical energy field is perturbed by the rubble zone and is differentiable from the effect of the geologic layering shown in the figure. On the other hand, the rubble zone in (b), embedded in a layer that is block faulted, is very difficult to differentiate from the geologic layering. This figure is a generalization of the geologic structure under Yucca Fat at the Nevada Test Site. Differentiation of these structures, difficult with current technology, is an active area of research. 


\section{On-site Inspections}

(c)

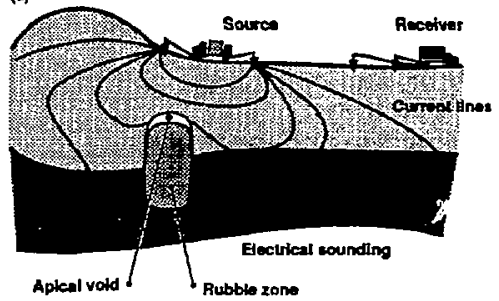

(1)

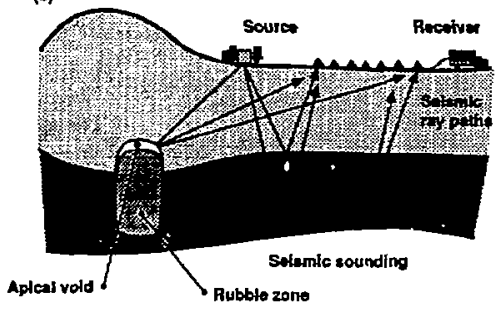

The process of geophysical sounding introduces (a) alectric, (b) seismic and other types of energy into the ground and detects the returned signal.

(a)

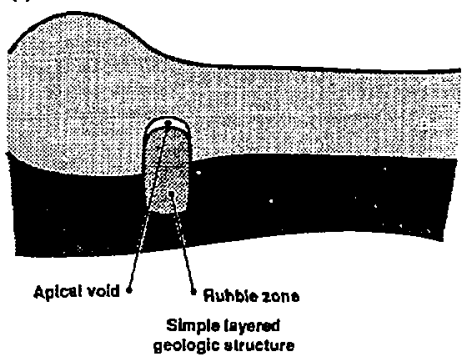

(b)

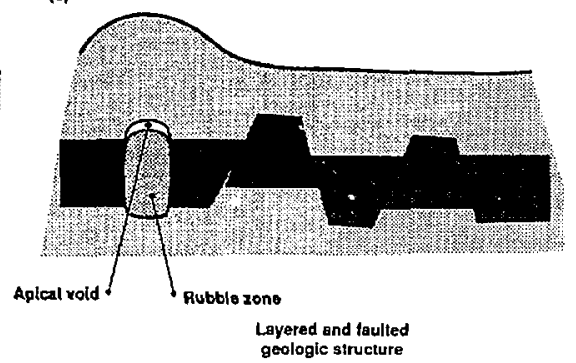

(a) Rubble zone in environment with little gealagic clutter. (b) Rubble zane in environment with severe geologic clutter. 


\section{Other technologies could be used to monitor large, declared explosions}

For large, declared mining explosions, as shown in the figure, the party carrying out the explosion may want to invite an observation team to the site to assure the international community that the explosion is not being used to mask an undeclared clandestine nuclear explosion. The monitoring party (in the truck) would want to consider carrying out all the measurements discussed above, in addition to some measurements that could be taken at the time of the explosion. One such measurement could be on-site, extremely-low-frequency electromagnetic measurements. The figure shows an example of such measurements taken within 1 kilometer of both a nuclear and a chemical explosion. Note that the nuclear explosion shows a large puIse at zero time, which is not evident on the graph of the chemical explosion.

\section{Conclusion OSI technologies are sufficiently developed to offer a credible cieterrent}

In locating and detecting a clandestine nuclear test, two OSI technologies in particular can have a strong role: aftershock detection and soil gas analysis. These technologies will be effective in most geologic environments and have both broad and narrow search capabilities. In addition, it may be possible to use geophysical sounding techniques when enough is known about the geologic environment to predict the degree of clutter and accusacy. 
Experiment geometry

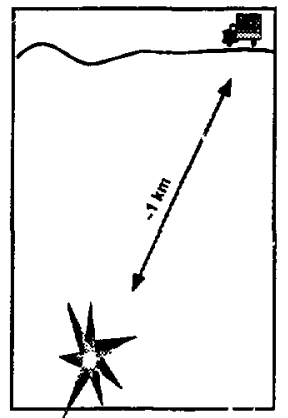

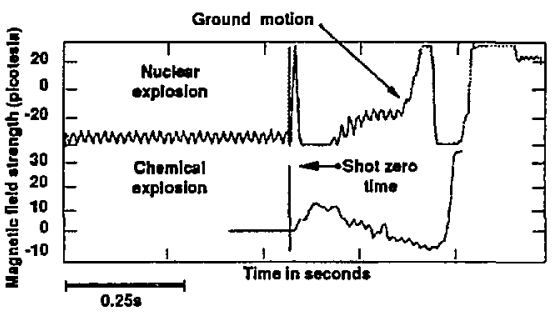

A possible tech. nology for confidence-building deployments is extremoly-lowfrequency electromagnetic Tonitoring. The ct iemical explosion signal was generated by a 1-kiloton chemical detonation in Rainier Mesa at NTS. The nuclear signal is from a nearby nuclear explosion of comparable yield. Late-time signal structure is due to shock-induced ground motion at the sensor location. 


\section{introduction}

This section discusses issues and factors that should be considered when selecting a set of verification measures. Discussions about verification measures often focus on whether the verification capability they provide is sufficient. In this section, a distinction is made between the verification ca,ability and the benefit of a set of verification measures. Verification capability is defined as the ability to detect nuclear tests and to distinguish them from other events such as earthquakes and chemical explosions. The ber it of a set of verification measures depends on the verification capability the measures provide, and also on the likelihood of violations in the different environments and the value of being able to distingtish between nuclear tests and other everts. Selection of a set of verification measures requires determining the desired balance of verification capabilities across the various test environments. For a given cost, different allocations of verification measures may result in very different benefits. On the following pages we discuss the factors that affect the berefit of a set of verification measures and describe the role they might play in the selection of verification measures. Other factors such as policy objectives, which may also play a role in the selection of verification measures, are not addrassed in this section.

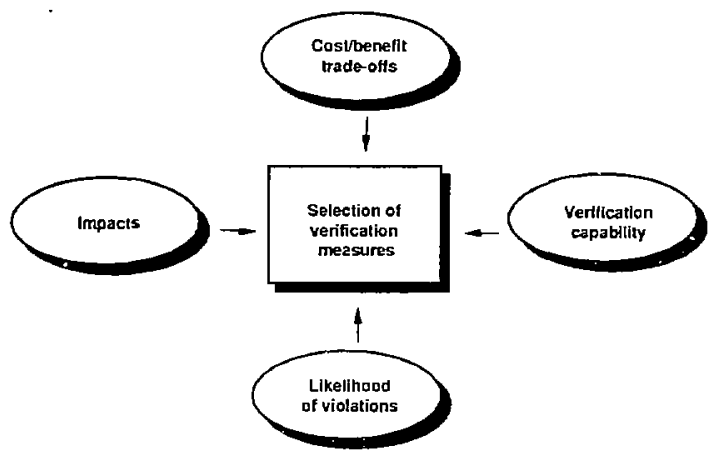

This section discusses major factors that should be considered when selecting veritication measures. 


\section{Verification capability depends on the ciegree of ambiguity in monitoring data}

Verification capability is a measure of the ability to detect nuclear tests and to distinguish them from "other events," which include any natural cr man-made event that may be mistaken for a nuclear test. Verification capability may vary for different test environments (underground, underwater, in the atmosphere, or in space) and geographical regions. Thus, it should be discussed in the context of a spexific environment, for example, underwater tests in the Indian Ocean. The monitoring data generated by nuclear tests and other events are of a random nature and there may be overlap between the potential measurements that could be generated by the two. This overlap represents the degree of ambiguity in the monitoring data. In other cases, verification measures may not be sufficient to detect a nuclear test at all. In this case, no monitoring data is generated by the event.

The randomness of the data generated by an event is represented in a "likelihood function," which indicates the relative likelihood of obtaining the various potential data measurements as a result of the event. The degree of ambiguity in monitoring data is incicated by the overlap of the likelihood functions for data generated by nuclear tests and "other events"; the greater the overiap, the lower the verification capability.

\section{The interpretation of monitoring data has four potential results}

Because of the ambiguity il cherent in monitoring data, there is a potentiai for arriving at the wrong conclusion. Hence, the interpretation of monitoring data has four potential results: two in the case where a teaty violation (I.e., a nuclear test) has actually occurred and two in the case where no violation has occurred. The four potential results are:

- Recognized violation - a correct conclusion that a violation has occurred.

- Missed violation - failure to recognize that a violation has occurred.

- Recognized compliance - a correct conclusion that no violation has occurred.

- False accusation - a conclusion that a violation has occurred when, in fact, none has. 


\section{Selecting Verification Measures}

(a)

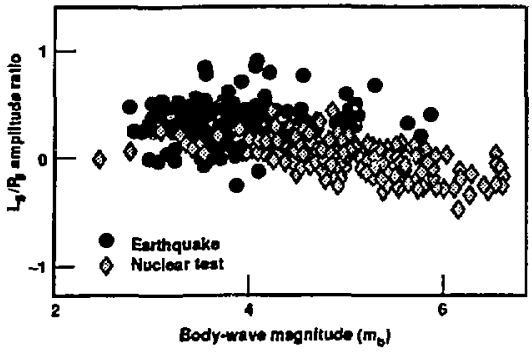

(a) Seismic discriminant based on amplitudes of seismic wavetypes $L_{g}$ and $P_{g}$. Nuclear tests and "other events" (e.g., earthquakes) may genorate similar measurements. Hence, monitoring data can be ambiguous. (b)

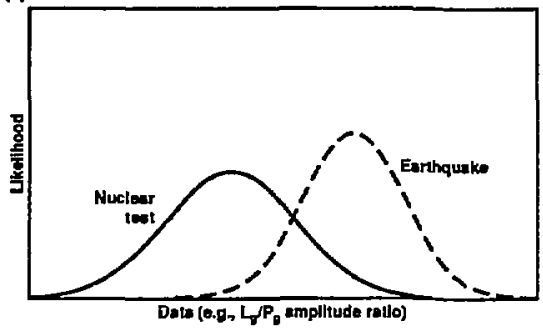

(b) "Lkellhood functions" show the relative likelihood of obtaining various data measurements as the result of an evert. Greater overlap of the likelihood functions for data generated by nuclear tests and "other events" (e.g., earthquakes) implies lower verification capability.

Event
Earilear test $\rightarrow$ (generates duta) $\rightarrow\left\{\begin{array}{c}\text { Nuclear test } \\ \text { "Other event" }\end{array}\right]\left\{\begin{array}{c}\text { Recognized violation } \\ \text { Missed violation }\end{array}\right]$

The imterpretation of monihoring data has four potential results: two in the case where a trealy violation has occurred and two in the case where no viclation has occurred. 


\section{Verification capability is quantified by the probabilities of false accusations and missed violations}

Based on the data obtained from verification measures, a judgment must be made as to whether or not an event was a nuclear test. This judgment typically will be based on whether the obtained data measurement falls above or below a specified threshold, that is, the decision line. The probability that "other events" will generate a data measurement on the "conclude event was nuclear test" side of the decision line is the probability of false accusation. Likewise, the probability that a nuclear test will generate a measurement on the "ignore event" side of the decision line is the probability of missing a violation given that a detectable violation occurs. The probability that a nuclear test will not be detected at all, i.e., that no data measurement will be generated, must be included in the total probability of missing a violation.

When selecting a decision line, a trade-off must be made between the probabilities of false accusations and missed violations. By changing the decision line, one probability can alwavs be decreased at the expense of increasing the other. In the figure at right, moving the decision line to the left decreases the probability of false accusation while increasing the probability of missed violations. Moving it to fie right does the opposite. One way of selecting the decision line is to specify an acceptable probability of false accusation and set the decision line accordingly. Alternatively, one may set the decision line in order to achieve a specified probability of recognizing a violation. One may also set the decision line to optimize the trade-off between false accusations and missed violations based on their relative impacts and the likelihood of violations. 


\section{Selecting Verification Measures}

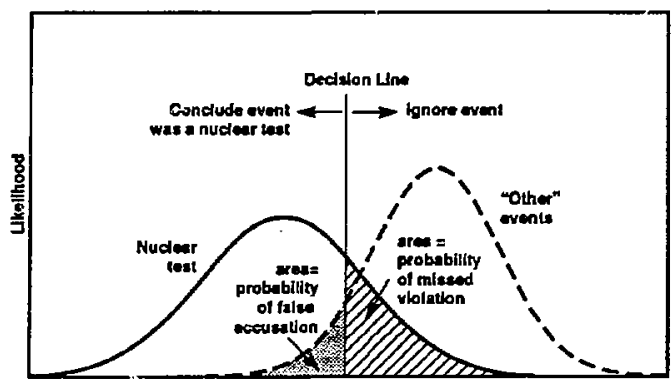

Monitoring date

Interpretation of monitoring data is based on whether the data measurement falls above or below a specified threshold. This "decision line" determir ss the probabilities of false accusation and missed violation. 


\section{Selecting Verification Measures}

\section{The likelihood of tests affects the desirability of improving verification capabilities in different environments}

The benefit of improving verification capabilities in a particular environment depends on the likelihood that a nuclear test will occur in that environment. The likelihood that a clandestine nuclear test will be performed and, assuming it is, the likelihood that a particular test environment (underground, underwater, atmosphere, or space) will be selected, may vary widely for different countries. Cost, technical difficulty, and probability of detection (i.e., verification capability) may influence both a country's propensity to conduct a violation and its choice of test environment. Certain test environments may not be feasible for some countries.

Improving verification capabilities for environments in which the countries of high concern are most likely to test will generally provide the greatest additional benefit. However, because verification capability may influence both the propensity to test and the choice of environment, maintaining an appropriate balance of verification capabilities among the different test environments is important. Improving monitoring in an environment of high concem is only beneficial up to the point where a different environment becomes a greater concern. See the table for an example scenario. 


\section{Additional benefits scenario}

Suppose country A and country B both have a high probability of testing, country A is most likely to test underground, and country $A$ is most likely to test in an coean. Improving undenground monitoring capabilities in coumtry A's territory and improving underwater monitoring capabilities in the ocean probably have much higher values than improving underground monitoring in country B's territory. However, suppose that menitoring improvements in county $A$ and in the oceans have been made and that country $A$ now has a low probability of testing and country $B$ is most likely to test underground. Improving underground monitoring capabilities in country $B$ may riow have a higher value than making addriona improvements in country $A$ and in the oceans, or making any improvements in monitoring country $C$.

\begin{tabular}{|c|c|c|c|c|}
\hline \multirow[b]{2}{*}{ Country } & \multicolumn{2}{|c|}{$\begin{array}{l}\text { With current } \\
\text { verification measures }\end{array}$} & \multicolumn{2}{|c|}{$\begin{array}{l}\text { After improving verffication } \\
\text { measures in problem areas }\end{array}$} \\
\hline & $\begin{array}{l}\text { Likelihood of } \\
\text { violation }\end{array}$ & $\begin{array}{l}\text { Likely test } \\
\text { environment }\end{array}$ & $\begin{array}{l}\text { Likelihood of } \\
\text { violalion. }\end{array}$ & $\begin{array}{l}\text { Likely test } \\
\text { environment }\end{array}$ \\
\hline Country A & H & 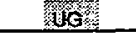 & L & UG \\
\hline Countor B & $\mathrm{H}$ & (x) & $\mathrm{H}$ & 後 \\
\hline Country $\mathrm{C}$ & $L$ & ATM & $L$ & ATM \\
\hline
\end{tabular}

$t=$ low concom; $H=$ high concem; $U G=$ underground: $U W=$ undel water ATM = atmaspheric

The lable shows the likelihood of violation and Bkely choice of test environmemt for three countries under two diflerent siluations, Shading indicates whera improvemems in monitoring capability are likely to be most productive. Note ind as monitoring capability changes, the most produxtive areas for improvement may also change. 


\section{The benefit of improved verification depends on the relative impacts of correct and incorrect compliance judgments}

In addition to the likelihood of violations, the benefit of improved verification also depends on the relative impacts of the potential recults of verification: recognized compliance, false accusations, recognized violations, and missed violations. Recognized compliance is, of course, the most desirable situation. The other three outcomes are assumed to have an adverse impact relative to recognized compliance. The degree of these impacts depends on military, political, and possibly other considerations. The adverse impact of a missed violation is assumed to be greater than that of a recognized violation. The difference between the impacts of missed and recognized violations reflects the value of recognizing a violation and depends on the degree to which knowledge of a violation and the response to it mitigate the impacts. The adverse impact due to a false accusation may be greater than, less than, or in between the impacts of missed and recognized violations. Because these impacts depend on military and political factors, they must be assessed on a country-by-country basis.

Given that a certain amount of monetary resources will be spent on improving verification capability, how to allocate these resources among the different test environments must be decided. As already noted, it is generally more desirable to improve verification capabilities in environments of concem as opposed to ones in which a siolation is not likely to occur. The value of improving monitoring capabilities depends on three factors:

- Deterrence. A country's propensity to conduct a nuclear test may decresse as verification capabilities increase. The degree of deterrence depends on the the country's aversion to having a violation recognized. The resul ing benefit depends on the magnitude of the adverse impacts of violations that 3 re avoided as a result of det irrence.

- Value of recognizing violations. Assuming a violation occurs (i.e., Lett'irence fails), improved verification capability results in a higher probability of recopnizing the violation. The amount of benefit obtained from this depends on the degree to which recognizing the violation lowers its adverse impact

- Impact of false accusations. In addition to increasing the probability of recognizing violations when they occur, improvements in verification capability may also be used to lower the probability of false accusation. The benefit obtained from lowering this probability depends on the magnitude of the adverse impact resulting from a false accusation. 

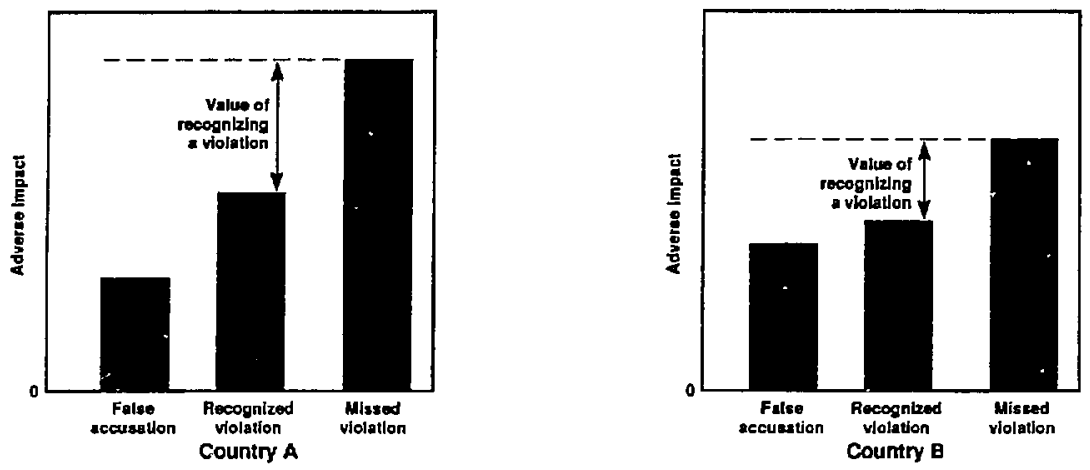

The value of improving monitoring capabilities depends on the relative impacts of the potentiat outcomes. The magnitude of these impacts will vary for different countries. 


\section{Verification should be cost effective}

When deciding whether a set of verification measures is adequate, one should consider the trade-off between benefit ana cost. As already noted, the total benefit of a set of verification measures depends on three factors:

- Verification capability.

- Likelihoods of various types of potential treaty violations.

- Impacts of recognized compliance, false accusations, recognized violations, and missed violations.

The cost of a set of measures includes equipment and maintenance costs, operation costs, and costs associated with gathering and interpreting the data. As discussed previously, for a given cost, different aliocations of verification measures may result in very different bcnefits. Assuming care is given to optmizing the allocation of verification resources, total benefit increases with cost. However, the marginal increase in benefit per unit cost typically decreases as cost increases.

The figure at right shows a typical cost/benefit trade-off curve. Costeffective allocations of verification resources are those that lie on the steep portion of the cost/benefit curve. The flattening of the curve at higher costs is due to two primary factors.

- Beyond the level of verification capability sufficient to achieve deterrence, improved verification provides no additienal benefit. For example, if a 50 percent chance of recognizing a violation is sufficient to deter a country from conducting a violation, there is ino benefit to improving the probability of recognizing a violation by that country beyond 50 percent.

- As verification capability improves, additional improven ients in capability become very expensive and may not even be feasible.

\section{Verification may combine routine monitoring with special investigatory measures}

Thus far, for simplicity, verification has been discussed in the context of routine continuous monitoring. Verification may be a two-stage process consisting of routine moritoring and nonroutine investigatory measures such as on-sitt inspections to investigate suspicious underground events. For example, in evaluating the data obtained from routine monitoring, rather than conclude that a nuclear test has or has not occurred, one may decide to further investigate an event.

In deciding when to implement investigatory measures, one must consider the degree to which the measures provide better resolution between nuclear tests and "other events," the costs, and the limits on the number of investigations allowed. The threshold for triggering investigatory measures determines the expected number of investigations and, hence, affects the cost of verification. 


\section{Selecting Verification Measures}

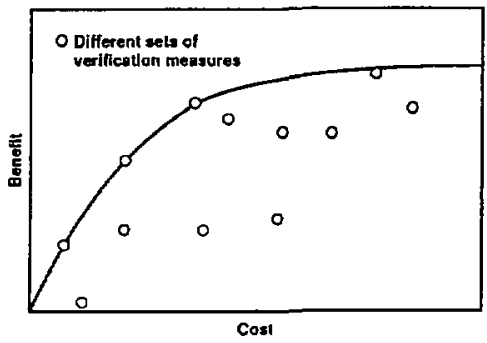

The marginal

increase in benefit per unit cost typi-

cally decreases as cost increases.

Verilication measures falling on or near the steep portion of the cune are most desirable from a cost/benefit perspective.

When data from routine monitoring is ambiguous, one may elect to implement inyestigatory measures

(e.g., on-site inspections) 


\section{The problem of attribution may affect the desired allocation of verification resources}

In the previous discussions, the problem of attributing a nuclear test to a specific country was not considered. As noted in Section 3, attribution may be particularly difficult for tests conducted in or above the oceans. Inability to attribute a nuclear test to a specific country is likely to lower the degree to which the impacts of the violation can be mitigated, thus lowering the value of recognizing the violation. In addition, the probability of attribution may influence both a country's propensity to violate the treaty and its choice of test environment. Hence, if the probability of attribution is low for a particular test environment, one should take this into consideration when evaluating the benefit of improving monitoring capabilities in that environment.

Furthermore, if improverrients in the probability of attribution can be obtained at reasonable cost, one should consider whether improving attribution is of greater value than making other verification improvements. 


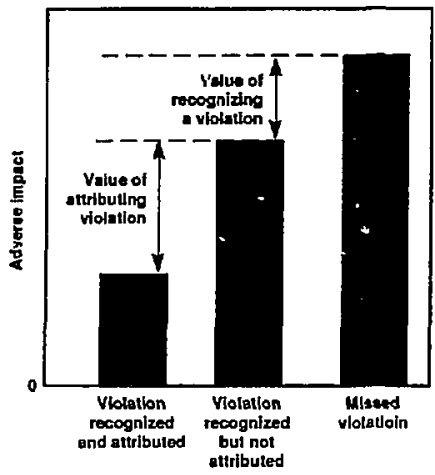

Inabitity to attributio a nuclear test to a specilic oountry may tower the value of recognizing a violation. When the proba. bility of attribution is low, improving atribution capabilsy may be of greater value than other verification improvements. 


\section{Glossary}

AEDS

AFMS

AFTAC

aftershocks

air fluorescence

alluvium

ARPA

array (seismic)

aseismic region

asthenosphere

attenuation

background radiation
Atomic Energy Detection System is a network of seismic sensors operated by the Air Force Technical Applications Center (AFTAC).

Automated Frequency Management System for EMP detection. (See electromagnetic pulse.)

Air Force Technical Applications Center.

Smaller earthquakes following the largest earthquake of a series concentrated in a restricted crustal volume. Small aftershocks also occur near the detonation point of underground nuclear explosions.

(also Tellex light). Visible and ultraviolet radiation in the air predominanty caused by gamma rays from the device exciting air molecules via inelastic scattering.

An unconsolidated sedinkent composed of sand, gravel, and clay that had been deposited by water.

Advanced Research Projects Agency of the Department of Defense.

A cluster of seismometers distributed over a fairly small area, usually a few kilometers. The signals from the individual instruments are combined to jmprove the detection and identification of any small or weak signals. The array can be "steered" like a phased array radar to waves from a particular direction, thereby enhancing these signals compared to the background noise.

A portion of the earth's crust that is relatively free of earthquakes. Normally, the region is larger than approximately $500 \mathrm{~km}$ in linear extent. The zones are within tectonic plates rather than at the edges of plates where most sarthquakes and volcanoes occur. (Actually, al? areas show some seismicity o ver a sufficiently long interval.)

Th.e world wide layer below the crust which is marked by low seisnsic wave velocities and high seismic attenuation. The asturenosphere is a soft layer, probably partially molten.

Reduction in intensity of a signal or wave as a result of absorption and scattering out of the path $y$ a detector, but excludes the reduction due to the geometricil effect from increasing distance. This decrease depends on the physical characteristics of the transmitting media.

Naturally cccurring nuclear (or ionizing) radiation arising from within the body and from the surroundings to which individuals are al ways exposed. The main sources of background radiation are potassium- 40 in the body; potassium-40, thorium, uranium, and their decay products (including radium and radon) that naturally uccur in rocks and soil; and cosmic rays. Fallout from: past atmospheric tests is now part of background problem for monitoring a CTBT. 
basalt

base surge

basin

batholith

beam

bearlorming

bhangmeters

bias

blast yield

body waves

borehole seismometers

boosted fission weapon
A fine-grained, dark, igneous rock-

A cloud that rolls outward like a fluid from the bottom of the column produced by a subsurface explosion whose fireball breaches the surface. For underwater bursts the visible surge is, in effect, a cloud of liquid (water) droplets with the property of flowing almost as if it were a homogeneous fluid. For underground bursts, the surge is made up of small solid particles but it still behaves like a fluid. Soft earth favors formation of base surges in an underground blast.

In tectonics, a circular, syncline-like depression of strata. In sedimentology, the site of accumulation of a large thickness of sediments.

An irregular mass of coarse-grained igneous tock with an exposed surface of more than 100 square kilometers, which has either intruded the country rock or been derived from it through metamorphism.

The average wavefront from the combination and summation of shifted waveforms frorn each seismometer in an array. The shifting is performed to enhance signais arriving from specific directions and distances.

The process of shifting and adding the recorded waveforms from each seismometer within a seismic array. The time shifting allows for the propagation time of the waves across the array and allows for "steering" the array towards a specific point on the Earth's surface for a specific wave type such as $P$-waves. The summation of waveforms tends to suppress the seismic noise since it usually varies randomly from sensor to sensor.

Sensors on satellites designed to detect the visible light flashes associated with atmospheric explosions.

Systematic error between true value and measured values. In seismic verification, "bias" refers to a possible systematic difference between magnitude estimates for equivalent yields at the Nevada Test Site versus the Soviet Test Si os or other test sites.

That portion of the total energy of a nuclear explosion that manifests itself as a blast (or shock) wave.

Seismic waves that propagate within an unbounded continuum are called body waves, as opposed to surface waves, which propagate along the boundary surface.

Installation of seismic sensors within a deep hole (normally 4 to 9 inches in diameter and 10 meters or greater in depth) reduces the influence of wind on the seismic noise. The RSTN seismometers and the NRDC-Soviet Academy of Sciences use $100 \mathrm{~m}$ boreholes and show a marked reduction and less variation in seismic noise. Reflection of the seismic wave from the Earth's surface can complicate the signal recordings within a borehole. Only limited data is available for deep boreholes at high frequencies.

A weapon in which neutrons produced by themonuclear reactions serve to enhance the fission process. 
bubble pulse

burst

cavity

CBM

chemical explosions (conventional explosions)

clean weapon

cloud column

coda

compliar, 'e

condensation cloud

contained underground explosion
When the detonation is sufficiently deep, the thermal radiation and sinock pressure rzults in a bubble of expanding gas which is contained in the water. The pressure pulse and bubble oscillate and reflect the dynamic equilibrium of the bubble pressure, the momentum of the water and gas, and the hydrostatic pressure of the surrounding water column. A discrete frequency is generated associated with the oscillation of the bubble. The oscillations diminish in amplitude as the bubble rises until the bubble breaks the water surface, or the spherical symmetry is broken. The resulting acoustic waves can be detected at great distances in the SOFAR channel and can also couple into the earth as seismic waves with a unique signature. (See SOFAR; SOSUS.)

Explosion or detonation. The voly me created by an underground nuclear explosion due to the melting, fracturing, and compression of the surtourding rock.

An underground nuclear explosion generates a cavity whose radius depends upon the device yield. Depending upon the geological medium, the cavity may collapse and generate a rubble zone or chimney, or it can remain as a large free-standing cavity. (See decoupling; rubble zone.)

Confiderice building measures.

Explosions typically used for minirg operaticns, corstructions, and industrial applications. Qr arsy operations can often involve explosions of 500 tons or more; single, kiloton shots also occasiorally occur and may represent a problem for seismic verification. (See also ripplu-firing.)

A nuclear weapon in which measures have been taken to reduce the amount of residual radioactivity relative to a "norma!" weapon of the same energy yield.

The visible column of weapon debris (and pcssibly dust and water droplets) extending upward from the point of burst of a nuclear weapon.

The portion of the seismogram of an earthquake that shows some vibrations long after the passage of body waves and surface waves. They are believed to be back-scattering waves due to lateral inhomogeneity distributed throughout the Earth's crust and upper mantle.

The adherence of a signatory country to the limits of an am s control agreement.

A mist or fog of minute water droplets which temporarily surrounds the fireball following a nuclear delonation in a comparatively humid atmosphere. It occurs in the rarification phase after the shock wave passes; this allows the temporary condensation of water vapor. The phenomenon is sometimes called the cloud chamber effect.

An underground detonation at such a depth that none of the radioactive residues escape through t: : surface. 
converted waves

core

coupling

crater

critical mass

cube root law

CWC

debris

decay

DARPA
Conversion of seismic waves to different types whan an incident on a surface or discontinuity for occurs. Converted waves sometimes show distinct arrivals on the seismogram between the $P$ and $S$ arrivals, and may be used to determine the location of the discontinuity.

The central part of the Earth beiow a depth of $2900 \mathrm{~km}$. It is thought to be composed of iron and nickel and to be molten on the outside with ? central solid inner core.

A measure of the fraction of the total energy released in an underground explosion that is transformed into seismic waves in the earth. The greater the coupling of a particular explosion, the greater the seismic waves. Longer seismic waves make the detection of an explosion and the discrimination of an earthquake (which has a different seismic signal) easier. The detonation of a nuclear explosion in a large salt cavity or other appropriate medium can "decouple' the seismic energy released, which would make detection and 'iscrimination more difficult and may permit evasion of threshold test limits and a comprehensive test ban.

The pit, depression, or cavity formed in the surface of the earth by a surface or underground explosion. If we start with an air blast and order the mechanisms by increasing depth below the surface, crater formation oscurs by vaporization of the surface material, by scouring effect of the air blast, by throwout of disturbed material, or by subsidence of earth into the cavity formed by the explosion.

The minimum mass of fissionable material that will just maintain a fission chain reaction under precisely specified conditions, such as the nature of the material and its purity, the nature anc. thickness of the tamper (or neutron reflector), the density (or compression), and the physical shape (or geometry). For an explosion to occur, the systen must be supercritical; the mass of material must exceed the critical mass under the existing conditions. (See supercritical.)

A scaling law applicable to many blast phenomena. For example, the time and distance at which a given blast effect is observed is proportional to the cube root of the energy yield of the explosion. The relationship arises, in part, because the volume (depending on distance cubed) is directly related to yield.

Chemical Weapons Convention.

(or weapon debris). The highly radioactive material, consisting of fission products, various products of neutron capture, and uranium and plutonium that have escaped fission, remaining after the explosion.

(or radioactive decay). The decrease in any radioactive material or its activity with the passage to time due to the spontaneous emission from the atomic nucle of either alpha or beta particles and sometimes gamma radiation. (See half-life.)

Previous name of ARPA. 
decision line

decoupling

density

depth of burial (DOB)

depth phases

detection

deuterium

diagnostics

discrimination

dome

dose
In dexision analysis, the value chosen as the basis for reaching one of two conclusions. Its choice reflects a trade-off between compliance and violation probabilities.

Involves detonating a nuclear device in a large underground cavity so as to muffe the seismic signal. Increasing the cavity volume reduces the explosion stresses on the cavity wall, which in turn reduces the seismic signal. When the stresses do not exceed the elastic limit of the rock, the explosion is said to be fully "decoupled" and the seismic signal becomes greatly reduced. At low frequencies, full decoupling may reduce the signal by at least a factor of 70; at high frequencies, the decoupling factor is reduced to as little as a factor of 7.

The mass per unit volume of a substance, commonly expressed in grams/cubic centimeter.

Refers to the der:h below the surface used for the detonation of an underground ruciear explosion.

Seismic phases which include a reflection of the upgoing wave at the Earth's surface near the explosion. The symbol pP has been used for P-waves propagated upward from the hypocenter, tumed into downward propagating $P$-waves by reflection at the free surface, and observed at teleseismic distances. sS, sP, and pS have analogous meanings. For example, sP corresponds to a phase that ascends from the focus to the surface as $S$ waves and then, after reflection, travels as $P$-waves to the recording station. These phases are useful for an accurate determination of focal depth for events greater than about $30 \mathrm{~km}$ when the depth phase can be separated.

Recognition that an event has occurted by a technical collestion system, but its identification (i.e., nuclear explosion, chemical sxplosion, earthquake, rock burst) has not been determined.

An isotope of hydrogen of mass 2 used in thermonuclear fusion. The hydrogen component of "heavy water," it is extracted from water at a ratio of 1 part detuterium to 6500 parts "light" hydrogen. (See also tritium.)

Instrumentation used to evaluate the characteristics of a nuclear detonation. Underground explosions may employ sophisticated measurements and communications near the shot, or the ability to drillback. Normally, the equipment is arranged in a long canister with lines of sight to the device for underground explosions. The inifurmation must then be transmitted to a safe and accessible area before its destruction in the blast.

As used in nuclear test limitation verification, it is the ability to differentiate between underground nuclear explosions and earthquakes. This task is accomplished through the analysis of seismic and other data.

The mound of water spray thrown up into the air when the shock wave from an underwater detonation of a nuclear device reaches the surface.

A (total or accumulated) quantity of icnizing (or nuclear) radiation. The absorbed dose in rads represents the amount of energy absorbed from the radiation per gram of specified absorbing material. 
dose rate

drillback

dynamic pressure

earthquake

elastic limit

electromagnetic pulse (EMP)

\section{EMP}

epicenter

evasion

fallout

ult

fireball
The amount of jorizing (or nuclear) radiation which an individual or material would receive per unit of time. It is usually expressed as rads (or rems) per hour or millirads per hour. The dose rate is commonly a measure of the level of radioactivity in a contaminated area.

Sampling solici cores from an underground explosion. Gamma ray spectroscopy can be used to obtain fission yield with emplaced racers.

The air pressure which results from the mass air flow (or wind) behind the shock frcnt of a blast wave. It is proportional to the air density and to the square of the particle (or wind) velocity.

The violent oscillatory motion of the ground caused by the passage of seismic waves radiating from a fault along which sudden movement has taken place.

The maximum stress that can be applied to a body without resulting in a permanent strain or deformation. Elastic deformation occurs for applied stresses below the limit.

A sharp pulse of radiofrequency (long wavelength) electromagnetic radiation produced when an explosion occurs in an asymmetrical environment, especially at or near the earth's surface or at high altitudes. The intense electric and magnetic fields can damage unprotected electrical and electronic equipment over a large area.

See electromagnetic pulse.

The point on the Earth's surface directly above the focus or hypocenter (point a which the rupture occurs) of an earthquake.

Methods to elude detection by a seismic network or other methods. Major evasion concerns are: (1) Hide the explosion signal in the earthquake;

(2) decoupling explosion in large cavity and muffing seismuc signal; and

(3) masking nuclear explosion with a large, legitimate industrial explosion. Evasion scenarios set the lower limit on the monitoring capability.

The process or phenomenon of the descent to the earth's surface of particies contaminated with radioactive material from a radioact.:'e cloud, or applied to the contaminated particulate matter itself. Early or local fallout reaches the earth within 24 hours; delayed (or world wide) fallout consists of smaller particles "which ascend in to the upper troposphere and stratosphere and are brought tu all parts of earth over months to years by rain or snow.

A planar. ontly curved, or senies of planar fractures in the Earth's crust actoss w: there has been relative displacement. (See Elastic rebound thency.)

The luminous sphere of hot gases which forms a few millionths of a second after a nuclear explosion as the result of absorption by the surrounding medium of thermal $x$ rays emitted by extremely hot (several tens of millions degrees) weapon residues. The exterior of the fireball in air is initially sharply defined by the luminous shock front and later by the limits of the hot gases themselves (radiation front). 
first motion

fission

fission fraction

fission products

fission yield

fluence

flux

focal mechanism

focus

formation
On a seismogram, the direction of ground motion at the beginning of the anival of a P-wave. Upward ground motion indicates a compression; downward motion, a dilatation. In discrimination, an explosion should generate initial compression in ali directions, whereas an earthquake creates a pattern of compressions and rarefactions (ground first moves toward source). These may be dear for large events, but the first motion may be lost in the noise for small explosions or earthquakes.

The process whereby thi nucleus of a heavy element splits into generally two nuclei of lighter elements, with the release of substantial amounts of energy. The most important fissionable materials are uranium- $\mathbf{2 3 5}$ and plutonium239; fission is caused by the absorption of neutrons.

The fraction (or percentage) of the total yield of a nuclear weapon that is due to fission.

A general term for the complex mixture of isotopes produced as a result of nuclear fission. A distinction should be made between these and the direct fission products or fission fragments which are formed by the actual splitting of the heavy-element nuclei. Approximately 80 different fission fragments result from roughly $\mathbf{4 0}$ different modes of fission of a given nuclear species (e.g., uranium-235 or plutonium-239). The fission fragments, being radioactive, immediately begin to decay, forming additional (daughter) products, with the result that the complex mixture of fission products contains over 300 different isotopes of 36 elements. Some isotopes form from interaction with geologic material. The isotopes krypton-85 and short-lived isotopes of xenon are important diagnostics of the occurrence of an undergtound test. Argon-37 is conclusive evidence.

The portion of the yield of the nuclear device that was produced by fission of nuclei.

(or integrated flux). The integrated particle (neutron or photon) flux over time, expressed in units of particles per square centimeter. The absorbed dose of radiation (in rads) is related to the fuence.

(or flux density). The product of particle density (number of neutrons or photons per cubic centimeter) and the particle velocity. It is equal to the total number of pasticles per second passing in all directions through a sphere of 1 square centimeter crosi-sectional area and is related to the absorbed dose rate.

The pattern of first motions generated by an explosion or earthquake. The pattem mi $y$ be used to estimate the type of faulting (dip-slip or strike-slip) for an es. ihquake.

The point on an earthquake fault at which the rupture initiates; synonymous with hypocenter.

The basic unit for the naming of rocks in stratigrapıy: a set of rocks that are or once were horizontally continuous, that share some distinctive feature of lithology, and are large enough to be mapped. 
fusion

gas sampling

GPS/NDS

ground zero

GGETT-3

GTiN

guided waves

gun-type weapon

G-waves (Gn)

half-life

HEMP

Hertz (Hz)

hide-in-earthquake

(HE)
The process whereby the nuclei of light elements, especially those of the isotopes of hydragen, namely deuterium and tritium, combine to form the nucleus of a heavier element with the release of substantial amount of energy. (See thermonuclear.)

Procedure for sampling gas from underground detonation for gamma spectrometry and isotope dilution mass spectrometry. Ratios of tracers and fission products can be used to calculate yield.

Global Positioning Satellites and Nuclear Detection System.

The point on the surface of land vertically below or above the center of a nuclear detonation, frequently abbreviated to GZ.

Planned seismic monitoring and data exchange experiment ( -1995$)$ planned in the Ad Hoc Group of Scientific Experts, Conference on Disarmament, United Nations, Geneva.

Global Telemetered Seismic Network.

Waves trapped in a wave-guide by total reflections or bending of rays at the top and bottom boundaries. An example is the acoustic waves in the SOFAR channel, a low-velocity channel in the ocean. Since the absorption coefficient for sound in seawater is quite small for frequencies on the order of a few hundred cycles per second, transoceanic transmission is easily achieved. If we consider the Earth's surface as the top of a waveguide, surface waves, such as Rayleigh, Love, and their higher modes, are guided waves. The waves associated with a low-velocily channel in the crust or mantle may be interpreted as normal modes with concentration of energy in the channel. Where they can exist, guided waves may propagate to considerable distances, because they are effectively spreading in only two spatial dimensions.

(Gun assembly). A nuclear weapon in which the nuclear explosion c rends upon assembling very rapidly two or more pieces of fissionable mat: (each less than a critical mass) to form a supercritical mass.

Another name for Love waves, a long-period seismic surface wave. Becatsse the group velocity of Love waves in the Earth is nearly constant (4.4! $\mathrm{kc}$ ) over the period range from about $\mathbf{4 0}$ to $\mathbf{3 0 0}$ seconds, their wavefors ather impulsive.

The time required for the activity of a given radiaactive species to decrease to half of its initial value due to radioactive decay.

High-altitude electromagnetic pulse. (See electromagnetic pulse.)

Uuts applied to frequency and equivalent to cycles per second.

Evasion scenario which assumes that a small nuclear cest zuuld be conducted by detonating the explosion during or soon after an earthqu $* \mathrm{k}$ and concealing the seismic signal of the explosion within the seismic $s_{j}$ itil of the earthquakı. 
high-altitude burst

high frequencies

hydrogen bomb

hypocenter

IAEA

ICC

IDC

identification

implosion weapon

infrared

infrasound

inverse square law

ionosphere

IWG
Somewhat arbitrarily defined as a detonation over 100,000 feet altitude. At greater heights changes in the fireball phenomena alter the distribution of energy between the blast and thermal radiation.

For seismic verification, high frequencies are normally greater than $10 \mathrm{~Hz}$.

Applied to nuclear weapons in which part of the explosive energy is obtained from nuclear fusion (thermonuclear) reactions.

The point below the epicenter at which an earthqueke actually begins; the focus. Also used sometimes for ground zero (GZ).

International Atomic Energy Agenc,. Responsible for enforcement of nuclear material safeguards and add-ses key provisions of the NTT.

International Consultative Commission. Prototype of international organization used for on-site in nections as instituted by the Chemical Weapons Convention.

International Data Center. Under the GSE plan, it collects data from a global seismic network and distributes it to rational data centers.

The source of the event can 'w tetermined by analysis of data from a technical collection system. Usually the detection capability of a technical collection system is greater than the identification capability; it is more difficult to identify the event source.

A nuclear weapon in which the fission chain reaction occurs when the fissionable material (less than a critical mass) has its volume suddenly decreased by compression and, as the density increases, becomes supercritical. The compression is produced by detonation of a spherir: arrangement of ordinary high explosive, designed and fabricated to achieve a uniform, inwardly-directed implosion shock wave.

Electromagnetic radiation with wavelength between the longest visibie red (700 nanometers or $7 \times 10^{-4}$ millimeter) and about 1 millimeter.

A very low-frequency acoustic signal in the atmosphere generated by the upward acceleration of the ground and subsequent fallback produced by the shock wave from an underground detonation. This can propagate horizontally hundreds of kilometers and create a shock wave as it propagates upward into the rarefied atmosphere. The displacement of the ionosphere centered above the source can be detected by radar.

When radiation from a point source is emitted unifirmly in all directions, the amount received per unit area is inversely proportional to the square of the distance, assuming no absorption.

The region of the atmosphere with appreciable ionization extending from approximately 60 to $350 \mathrm{~km}$ altitude. The presence of charged particles there strongly affects the propagation of radio waves.

Interagency Working Group on Arms Control within the U.S. Govermment. 
kiloton

L (Le LR)

I.ASA

Lg waves

lithosphere

longitudinal waves

Love waves

low-velocity zone

magnitude

magnitude-yield formula

mantle

$\mathbf{m}_{\mathbf{r}}$

mean fr:e path
A measure of energy defined as $10^{72}$ calories or $4.2 \times 10^{19} \mathrm{ergs}$. This is approximately the energy released by the detonation of 1 kiloton (1000 tons) of TNT.

The symbol $L$ is used to designate long-period surface waves. When the type of surface wave is known, LQ and LR are used for Love and Rayleigh waves, respectively.

Large-Aperture Seismic Array. Developed during the 1960 s by the Vela program, the array was located in Montana and its seismometers extended over $200 \mathrm{~km}$. Designed for teleseismic phases, the array was the first for verification studies and produced important seismological studies. The array was phased out during the $1970 \mathrm{~s}$.

Short-period (1-6 seconds) large-amplitude arrivals with predominantly transverse (horizontal shear) motion. $\mathrm{Lg}$-waves propagate along the surface with velocities close to the average shear velocity in the upper part of the continental crust. The waves are observed only when the wave path is entirely continental. As little as $2^{\circ}$ of intervening ocean is sufficient to eliminate the waves.

The outer, rigid shell of the Earth, situated above the asthenosphere and containing the crust, continents, and plates.

Waves whose displacement is along the direction of propagation. For this reason, $P$-waves are also called "longitudinal waves."

Sitear-waves with horizontal motion confined near the Earh's surface by an increasing velocity with depth. They can exist, in general, in a vertically heterogeneous medium.

A region in the Earth, especially a planar layer, that has lower seismic-wave velocities than the region immediately above it.

A measure of earthquake size, determined by taking the common logarithm (base 10) of the largest ground motion observed during the arrival of a P-wave or seismic surface wave and applying a standard correction for distance from the epicenter.

Ari empirical relation bet ween magnitude $m$ and explosive yield $Y$, typically of the form $m=A+B \log Y$. Each term has an uncertainty dependent on the test site and instrumentation.

The main bulk of the Earth, between the crust and core, ranging from depths of about $4 \mathrm{C}$ to $3480 \mathrm{~km}$. It is composet of dense mafic silicates and divided into concentric layers by phase changes that are caused by the increase in pressure with depth.

Magnitude of an earthquake or explosion calculated from the amplitude of short-period P-waves.

The "average" path distance a particle (neutron or photon) traveis before undergoing a specified reaction in matter (with a nucleus or electron). 
megaton

microseisms

$\mathbf{M}_{\mathrm{s}}$

NORESS

NPT

NTM

on-site inspection (OSI)

OPCW

overpressure
Defined as $10^{15}$ calories or $4 \times 10^{22}$ ergs. This is approximately the energy that would be released by 1000 kilotons $(1,000,000$ tors) of TNT.

Continuous ground motion constituting background noise for any seismic experiment. Microseisms with frequencies higher than about $1 \mathrm{~Hz}$ are usually caused by artificial sources, such as traffic and machinery, and are sometimes called microtremors, to be distinguished from longer-period microseisms due to natural disturbances (e.g., surf). At a ty ical station in the interior of a continent, the microseisms have predominant periods of about 6 seconds.

Mohorovicic discontiñuity The boundary between crust and mantle, marked by a rapid increase in seismic wave velocity to mure than $8 \mathrm{~km} / \mathrm{s}$. Depth varies between $5 \mathrm{~km}$ under oceans to $45 \mathrm{~km}$ under continents. Abbreviated "Moho" or "M-discontinuity."

Magnitude of an earthquake or explosion calculated from the amplitude of the 20-second period Rayleigh waves.

Norwegian Regional Seismic Array is located north of Oslo and opened in 1984. Funded by DARPA and DOE, the array consists of 25 individual sensors arranged in 4 concentric rings with a maximum diameter of $3 \mathrm{~km}$; its specific design was a product of LLWL and Sandia cooperation.

Nuclear Non-Proliferation Treaty, signed by the U.S. in 1968 and ratified in 196 ?.

National technical means. Refers to verification using available technology that can be applied outside of a countries boundaries. Examples are seismic networks outside of the boundaries of target countries and satellite photography.

OSI refers to the monitoring of compliance by using inspectors or sensors from one country to examine or monitor the other party's installations and/or activities. OSI is by its nature an intrusive means or verification.

Organization for the Prohibition of Chemical Weapons, implemented in the CWC, has the authority to make determinations regarding cases of noncompliance, including recoinmending collective action by member states and, in serious cases, referral to the UN General Assembly (I RVGA) and UN Security Council (UNSC).

The transient pressure exceeding the ambient pressure that is manifested in the shock wave. The temporal variation of the overpressure depends upon the yield of the explosion, distance from the burst, and medium for the detonation. Peak overpressure is the maximum value at a given location and is usually experienced at the instant when the shock wave reaches the locition.

Preliminary Determination of Epicenters. A publication of the U.S. Geology Sinvey that lists times and locations of seismic events.

period
The time interval between the arrival of successive crests in a wave train; the period is the inverse of the frequency of a cyclic event. 


\author{
$\mathbf{P g}$ \\ plume \\ Pn \\ porosity \\ primary \\ provipt radiation
}

P-waves

rad

radionuclides

Rayleigh waves

refraction

regional

regional seismic waves

$\mathbf{R g}$
Propagation of $P$ over short distances (up to a few hundred kilometers) att:ibuted to direct $P$-waves propagating through the crust as designated by $g$ for the granitic layer. Propagation velocity is usually near $6 \mathrm{~km} / \mathrm{s}$.

Water and spray thrown up from an underwater burst of a nuclear weapo. and through which the gases formed in the explosion are vented.

The first arrival from seismic sources in the crust roresponds to waves refracted from the top of the $m=$ nile generally in the distance range from 150 to $2000 \mathrm{~km}$. Calle $+\mathrm{Pn}$, these waves are selatively small, with lorg-period motion followed by larger and sharper waves of shorter period ralled $\mathrm{Pg}$. which propagate directly through the crust.

The percentage of the total rock volume of a rock that is pore space.

In nuclear weapons jargon, a primary is a fissioning device used to generate high temperatures used in a thermonuclear weapon. (See thermonuclear.)

Radiation gen ated by the explosion and its jmunediate interaction with the medium. It includes gamma rays and neutrons from nuclear reactions, and also $x$ ray. reated as blackbody radiation arising from the high-temperature, rapid, high-density energy relesse. All forms are severely attenuated by air, water, and earth.

The first arrival on a seismogram are compressional waves, where $P$ stan.1s for "primary." The particle displacement associated with P-waves is alon? the direction of wave propagation. For tivis reason, P-waves are sometimes called longitudiral waves.

A unit of absorbed dose of radiation; it represents the absorption of 100 ergs of ionizing radiation per gram of absorbing material, such as body tissue.

Radioactive fission fragments coming directly from fission reactions (e.g-. krypton and $x$ (nion) or transmutations eaused by neutron-induced reactions (e.g., isotopes of uranium or plutonium).

Surface waves with strongest amplitudes that arrive late in the seismic signal.

The departure of a wave from its original direction of travel at an interface with a different (seismic) velocity.

Refers to distance between seismic source to receiver of approximately 150 to $2000 \mathrm{~km}$. Within this range the first aniving P-wave propagates along the interface between crust and mantle.

Seismic waves recorded between approximately 150 and $200 / \mathrm{km}$ from an event. These phases typicaliy propagate through the crust, and their characteristics are dominatea by the velocity and attenuation structure of the crust and upper mantle.

Short-period Rayleigh waves observed for continental paths are sometimes designated as $\mathbf{R g}$. 
Richter magnitude scale

ripple-fring

rockbursts

RSTN

rubble zone

scaling law

scaltering

seconaicry

seismicity

seismic reflection
See magnitude.

A procedure typically used to optimize the fragmentation of rock for mining blasts and chemical explosions for excavation. As such, the method is almost universally employed for large chemical explosions in industrialized countries. The method depends upon distributing the explosive charge between many adjacent boreholes (separated by a few feet to 30 feet and with a similar range in depths) and firing the charges in a predetermined pattem of time delays that successively blasts away a layer of rock before detonating the adjacent holes. The time delays can range from milliseconds to seconds. These delays are often periodic and may introduce strong spectral features within seismic signals generated by the chemical explosion. Also known as "delay-shooting."

Refers specificaly $\quad$ mass fractured off a mine wall or working face at high velocity. Somei., applied as a generic term for seismicity within deep mines (usually greater than $1 \mathrm{~km}$ in depth). Rockbursts are often just a triggered phenomena of a larger event involving fault slip or tunnel collapse within the mine; these seismic events can exceed magnitude 5.

Regional Seismic Test Network. Consisted of five seisnic stations developed for DOE by LLNL and Sandia during the late 1970s and now operated by the USGS. These high-quality borehole stitions were intended to be prototypes of in-country stations. The stations were deployed in the U.S. and Canada over geology and inter-station distances that would represent monitoring in the Soviet Union with 10 internal stations.

Collapse material falling into the cavity formed by an underground nuclear explosion. The zone typically takes the form of a chinuney above the detonation point; its collapse extends to the surface and a subsidence crater forms. (See crater.)

A mathematical relationship that permits the effects of a nuclear explosion to be determined from the yield and distance based on a reference explosion. (See cube root law.)

Thi diversion of radiation (radio, therma], nuclear) or seismic waves caused by its interactions with the medium during its propagation from the source. As a result of scattering, radiation or seismic waves will be received from many directions instead of ovty from the direction of the source.

In nuclear weapons jargon, a secondary is the second compon:ent of a thermonuclear device. (See boosted fission weapon; thermonuclear.)

The work-wide or local distribution of earthquakes in space and time; a general term for the number of earthquakes in a urit of time.

A mode of seismic prospecting in which the seismic profile is examined for waves that have reflected from structures or near-horizontal strata below the surface. 
seismic refraction

seismic surface waves

seismic travel times

seismograph

:ieismology

shock wave

slick

slip

$S_{n}$

SOFAR

SOSUS

spalt
A mode of seismic pros recting in which the seismic profile is examined for waves that have been refracted upward from seismic discontinuities (abrupt velocity changes) below the profile. Greater depths may be reached than through seismic reflection.

A seismic wave that follows the Earth's surface only, with a speed less than that of S-waves. There are Rayleigh waves (forward and vertical vibrations) and Love waves (transverse vibrations).

See travel-time curve.

An instrument for magnifying and recording the motions of the Earth's surface that are caused by seismic waves.

The study of earthquakes, seismic waves, and their propagation through the Earth.

A continuously propagating pressure pulse (wave) in the surrounding medium (air, water, or earth), initiated by the rapid expansion of hot gases produced in an explosion. In air, it is referred to as a blast wave and is distinguished by two phases: r-positive (compression) phase when the pressure rises very rapidly $a b$ ive ambient, followed by the negative (rarefaction or dilational) phas: when it falls more gradually below ambient. but with a much smaller deviation over a longer time.

The trace of an ad vancing shock wave seen on the surface of caln water as a circle of rapidly increasing size, often appearing darker than the surrounding water. It is observed following underwater explosions.

The relative motion of one face of a fault relative to the other.

Applied to a prominent arrival of short-period shear waves that may be observed to epicentral distances as great as $40^{\circ}$.and travel in a waveguide at the top of the mantle. Propagation for thort periods is more efficient, because longe:-period waves have a substantial fraction of their energy within higher attenuating material at greater depth, and hence are filtered out. Early use of the designation $S_{n}$ was in referenc to short-period $S$-waves that were presumed to propagate as head waves along the top of the mantle.

An acoustic waveguide within the ocean that allows very low-frequency :zund waves to propagate great distances. The depth of the channel varies primarily depends upon latitude, but is strongly dependent of any phenomena such as upwelling which changes the temperature distribution of the water column. (See bubble pulse.)

Sound Sui vesltance System of the U.S. Navy. A network c' ocean sensors designed to moruitor acoustic signals in the oceans. (See buible pulse.)

A lifting and separation of the near-surface ground as the shock wave from an underground explosion reaches the surface and accelerates the ground. After separtion, the near-surface layer (tens of meters) is in ballistic flight until the separation closes, known as slapdown. Deeper burial of the shot raduces or can ehminate spall and its resulting surface disturbance. (See crater; depth of burial.) 
spray dome

strike

subduction zone

superaitical

S-waves

Teller light

thermonaclear

tracer

travel time curve

tritium

USAEDS

wavelength
See dome.

The angle between true North and the horizontal line contained in any planar feature (inclined bed, dike, fault plane, etc.); also the geographic direction of this horizontal line.

A dipf -ng planar zone descending away from a trench and defined by high seismicity, interpreted as the shear zone between a sinking oceanic plate and an overriding plate.

Describes the state of a fission system when the quantity of fissionable material is greater than the critical mass under existing conditions. For an explosion, a highly supercritical system is essential to achieve a very rapid production of energy.

Elastic shear waves are called S-waves in seismology, $S$ standing for "secondary." The particle Hisplacement associated with S-waves is perpendicular to the direction of wave propagation. For this reason, $S$-waves are sometimes called transverse waves.

See air fluorescence.

The processes in which very high temperatures are used for fusion of light nuclei with the accompanying liberation of large quantities of energy. A thermonuclear bomb derives part of its expissive energy from the thermonuclear fusion reactions of deuterium and tritium; the high temperatures required to initiate fusion are obtained from a fission explosion.

Known quantiby of isctopic gas or refractory solid placed rear a device (or part of a device) that can be sampled following the explosion (see gas sampling and driliback\}. The device fission yield can be calculated from the measured ratio of the fission product to tracer.

A curve on a graph of travel time versus distance for the arrival of seismic waves from distant events. Each type of seismic wave has its own curve.

A radioactive isotope of hydrogen with atomic mass of 3; it is produced in nuclear reactors as neutron reactions in lithium nuclei. It is an important component of thermonuclear devices.

U.S. Atomic Energy Detection System. A global seismic system operated by AFTAC and also commonly referred to as hEDS.

The distance between two successive peaks, or between troughs, or a cyclic propagating disturbance. 
World-Wide Standardized Seismograph Network. In response to the Berkner Panel and the Geneva Conference of Experts in 1958, ARPA prepared a plan to upgrade an open international network of cooperative seismographic stations. The U.S. Coast and Geodetic Survey was charged with entering into agreements with various national observatories and installing the equipment. Between 1961 and 1967, standardized instruments ard clocks were installed in some 120 stations distributed in about 60 countries. Instrumentation was tumed over to the local observatories, and all reiords were kept in the country, to be used for whatever purpose was deened proper. The only obligations were that the local observatory send copies of the records to the U.S. Cosst and Geodetic Survey and that technicians from the Survey be allowed to service the instruments -aring the period of mutual agreement. After 1968, the US. Congress no longer appropriated funds to support or improve the WWSSN, and by 1971, only 90 stations made records available regulariy.

vield

(or energy yield) The total effective energy release in a nuclear explosion. It is usually expressed in equivalent tonnage of INT required to produce the same energy relesse. The total energy release manifests itself as nuclear radiation, thermal radiation, and shock energy; the actual distribution depends upon the shot medium and type of weapon. 